\title{
Having More Choices Changes How Human Observers Weight Stable Sensory Evidence
}

\author{
(DSirawaj Itthipuripat, ${ }^{1,2,3}$ Kexin Cha, ${ }^{4}$ (DSean Deering, ${ }^{4,5}$ Annalisa M. Salazar, ${ }^{4}$ and ${ }^{\oplus}$ John T. Serences ${ }^{3,4,6}$ \\ ${ }^{1}$ Department of Psychology and Center for Integrative and Cognitive Neuroscience, Vanderbilt University, Nashville, Tennessee 37235, ${ }^{2}$ Learning Institute, \\ King Mongkut's University of Technology Thonburi, Bangkok, 10140, Thailand, ${ }^{3}$ Neurosciences Graduate Program, University of California-San Diego, La \\ Jolla, California 92093-0109, ${ }^{4}$ Department of Psychology, University of California-San Diego, La Jolla, California 92093-1090, ${ }^{5}$ Health Services Research and \\ Development, Veteran Affairs San Diego Healthcare System, La Jolla, California 92161, and ${ }^{6}$ Kavli Foundation for the Brain and Mind, University of \\ California, San Diego, La Jolla, California 92093-0109
}

Decision-making becomes slower when more choices are available. Existing models attribute this slowing to poor sensory processing, to attenuated rates of sensory evidence accumulation, or to increases in the amount of evidence required before committing to a decision (a higher decision threshold). However, studies have not isolated the effects of having more choices on sensory and decision-related processes from changes in task difficulty and divided attention. Here, we controlled task difficulty while independently manipulating the distribution of attention and the number of choices available to male and female human observers. We used EEG to measure steady-state visually evoked potentials (SSVEPs) and a frontal late positive deflection (LPD), EEG markers of sensory and postsensory decisionrelated processes, respectively. We found that dividing attention decreased SSVEP and LPD amplitudes, consistent with dampened sensory responses and slower rates of evidence accumulation, respectively. In contrast, having more choices did not alter SSVEP amplitude and led to a larger LPD. These results suggest that having more options largely spares early sensory processing and slows down decision-making via a selective increase in decision thresholds.

Key words: decision threshold; divided attention; event-related potential; evidence accumulation; multiple-choice decision-making; steady-state visually evoked potential

\section{Significance Statement}

When more choices are available, decision-making becomes slower. We tested whether this phenomenon is due to poor sensory processing, to reduced rates of evidence accumulation, or to increases in the amount of evidence required before committing to a decision (a higher decision threshold). We measured choice modulations of sensory and decision-related neural responses using EEG. We also minimized potential confounds from changes in the distribution of attention and task difficulty, which often covary with having more choices. Dividing attention reduced the activity levels of both sensory and decision-related responses. However, having more choices did not change sensory processing and led to larger decision-related responses. These results suggest that having more choices spares sensory processing and selectively increases decision thresholds.

\section{Introduction}

Humans can adaptively evaluate information about competing choice alternatives to optimize goal-based decision-making.

Received Feb. 18, 2018; revised Aug. 7, 2018; accepted Aug. 14, 2018.

Author contributions: S.I. wrote the first draft of the paper; S.I. and J.T.S. edited the paper; S.I. and J.T.S. designed research; S.I., K.C., S.D., and A.M.S. performed research; S.I. and J.T.S. contributed unpublished reagents/analytic tools; S.I. and K.C. analyzed data; S.I. and J.T.S. wrote the paper.

This work was supported by National Institutes of Health Grant R01-EY025872 to J.T.S., the James S. McDonnell Foundation to J.T.S., the Howard Hughes Medical Institute International program to S.I., and Ministry of Science and Technology in Thailand Royal Thai Scholarship to S.I. We thank Thomas Sprague, Scott Brown, and Nuttida Rungratsameetaweemana for useful discussions.

The authors declare no competing financial interests.

Correspondence should be addressed to either of the following: Dr. Sirawaj Itthipuripat, Vanderbilt University, Department of Psychology, 301 Wilson Hall, 111 21st Avenue South, Nashville, TN 37203, E-mail:
However, the speed of decision-making decreases as more choices are available, a phenomenon referred to as Hick's Law (Hick, 1952; Hyman, 1953; see also Roe et al., 2001; McMillen and Holmes, 2006; Bogacz et al., 2007; Niwa and Ditterich, 2008; Furman and Wang, 2008; Albantakis and Deco, 2009; Leite and Ratcliff, 2010; Churchland and Ditterich, 2012; Ratcliff and Starns, 2013). This effect of having more choices is often modeled as an accumulate-to-bound process, in which slower response times (RTs) are due either to a reduction in the rate of sensory

itthipuripat.sirawaj@gmail.com; or Dr. John T. Serences, University of California-San Diego, Department of Psychology, 9500 Gilman Drive, La Jolla, CA 92093, E-mail: jserences@ucsd.edu.

D0I:10.1523/JNEUROSCI.0440-18.2018

Copyright $\odot 2018$ the authors $\quad 0270-6474 / 18 / 388635-15 \$ 15.00 / 0$ 

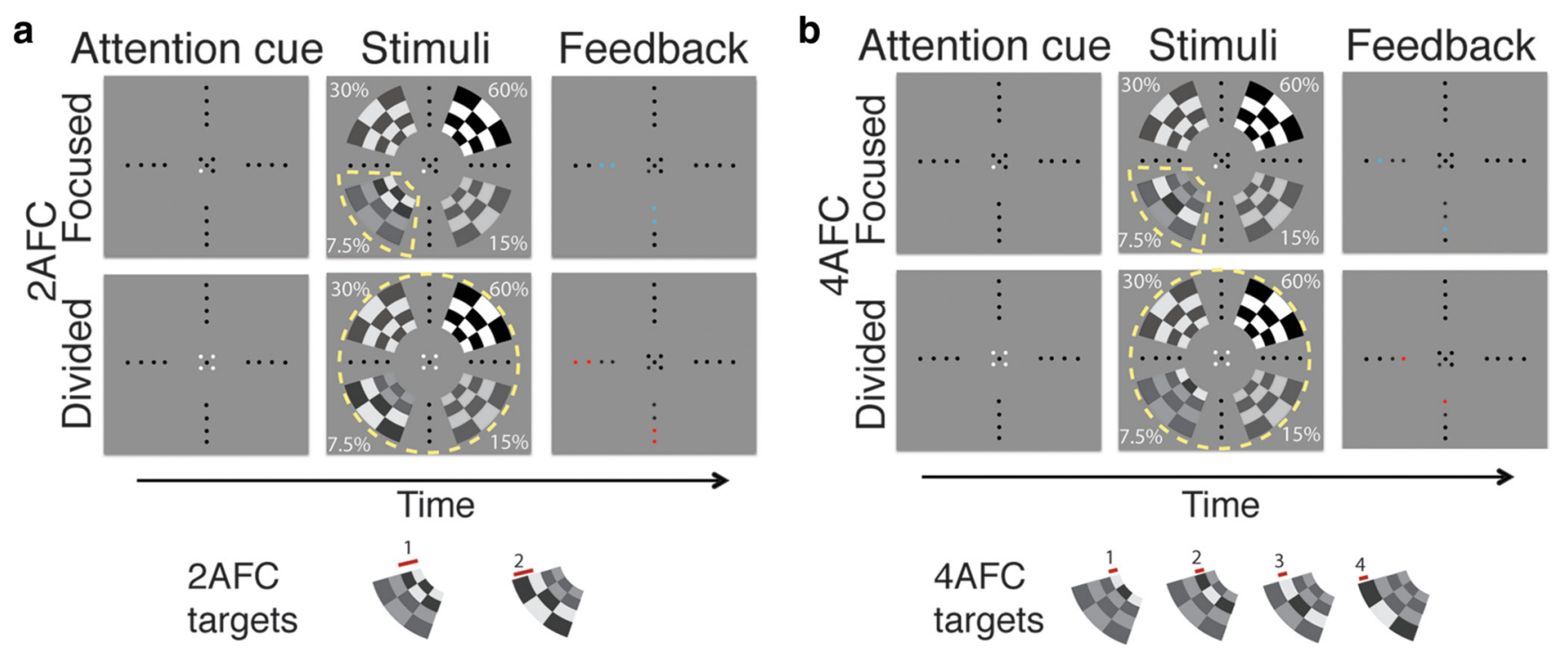

Figure 1. The 2AFC and 4AFC contrast discrimination tasks. $\boldsymbol{a}$, In the 2AFC task, subjects determined whether the inner or the outer segment of the target stimulus contained a contrast increment. $\boldsymbol{b}$, In the 4AFC task, subjects determined which of the 4 segments of the target stimulus contained a contrast increment. Across these two choice tasks, each trial started with either a focused or a divided attention cue. The focused attention cue pointed directly to the target stimulus, whereas the divided attention cue pointed to all stimuli ( 1 target and 3 nontarget stimuli). Feedback, which indicated the exact position of the contrast increment, was presented in blue for correct responses and in red for incorrect responses. The pedestal contrast of target and nontarget stimuli was pseudo-randomly and independently chosen from $0 \%, 3.75 \%, 7.5 \%, 15 \%, 30 \%$, and $60 \%$ Michelson contrasts. Percentage values indicate pedestal contrast values of individual target and nontarget stimuli in example trials. Task difficulty was equated at $\sim 76 \%$ across choice tasks, attention conditions, and contrast levels. To simultaneously measure SSVEPs evoked by individual stimuli, the visual stimuli on the upper left, upper right, lower left, and lower right quadrants were flickered at $30,17.1,20$, and $24 \mathrm{~Hz}$, respectively.

evidence accumulation or to an increase in the total amount of sensory evidence required before committing to a decision, which is typically associated with an increase in the decision threshold (see also Laming, 1968; Link and Heath, 1975; Busemeyer and Townsend, 1993; Smith and Ratcliff, 2004; Lo and Wang, 2006; Gold and Shadlen, 2007; Brown and Heathcote, 2008; Churchland et al., 2008; Luce, 2008; Ratcliff and McKoon, 2008; Ho et al., 2012a,b; Purcell et al., 2012; Wang, 2012; Ester et al., 2014; Keuken et al., 2015). Such an increase in the decision threshold has been proposed as an adaptive strategy to combat increased uncertainty that often accompany decisions with more alternatives (for review, see Churchland and Ditterich, 2012; Banca et al., 2015).

To test these different theoretical accounts, Churchland et al. (2008) examined the impact of having more choices on the firing rate of decision-related sensorimotor neurons in the lateral intraparietal (LIP) area. First, having more choices caused activity in LIP neurons to start at a lower baseline firing rate before increasing to a fixed response threshold. Second, activity in these neurons was slower to rise, which is consistent with a decrease in the buildup rate of evidence accumulation. Other studies also found that having more choices reduced the overall firing and accumulation rates of neurons in the LIP and the frontal eye field (FEF) (Balan et al., 2008; Cohen et al., 2009; Purcell et al., 2012). Together, these previous results suggest that having more choices attenuates over all neural responses measured in postsensory areas and reduces the rate of evidence accumulation.

So far, existing studies have not examined modulations in sensory cortex, so it is unclear whether choice-related reductions in neural activity in postsensory areas are inherited from earlier biases in sensory processing. Moreover, previous studies did not isolate the effects of having more choices from concomitant changes in the number of sensory inputs, the distribution of attention, and overall task difficulty. Controlling these additional factors is critical for several reasons. First, increasing the number of sensory inputs can increase neural inhibition via divisive normalization, which may then reduce overall neural activity during sensory processing and decision-making. Importantly, divisive normalization has been shown to occur even in passive viewing tasks as well as behavioral tasks where visual stimuli were not relevant to current decision-making goals (Heeger, 1992; Carandini and Heeger, 2011; Louie et al., 2013; Itthipuripat et al., 2015). Therefore, previous results might be driven largely by sensory rather than choice-related modulations. Second, divided attention and increased task difficulty are known to drive effects in parietal and frontal cortex that resemble the modulations attributed to increases in the number of choices. For example, dividing attention leads to reduced accuracy and longer RTs, and is associated with attenuated sensory responses and reduced decisionrelated neural activity in sensorimotor areas (Mangun and Hillyard, 1987, 1988; Palmer, 1994, 1995; Mangun and Buck, 1998; Awh and Pashler, 2000; Eckstein et al., 2000; McMains and Somers, 2004; Toffanin et al., 2009; Eckstein, 2011; Pestilli et al., 2011; Hara and Gardner, 2014; Itthipuripat et al., 2014a, 2017; Gardner, 2015; Wyart et al., 2015; Mayo and Maunsell, 2016; Arcizet et al., 2017; but see White et al., 2017).

Here, we isolated the effects of having more choices on both sensory and later decision-related processes by independently manipulating the number of choices and the distribution of attention while equating task difficulty across conditions (Fig. 1). Early sensory processing was indexed using the amplitude of steady-state visually evoked potentials (SSVEPs) following previous studies (Müller et al., 2006; Kim et al., 2007; Andersen and Müller, 2010; Kelly and O'Connell, 2013; Störmer et al., 2013; Itthipuripat et al., 2014b; Störmer and Alvarez, 2014; Norcia et al., 2015). The accumulation of sensory evidence during decisionmaking stage was indexed by the late positive deflection (LPD) component, which has been linked to postsensory decisionrelated processes (Hillyard et al., 1972; Squires et al., 1973, 1975; Mangun and Buck, 1998; O'Connell et al., 2012; Kelly and 
O'Connell, 2013; Itthipuripat et al., 2014a, 2015, 2017; Twomey et al., 2015; Wyart et al., 2015; Loughnane et al., 2016; Nelli et al., 2017; Rungratsameetaweemana et al., 2018). The connection between the LPD component and the properties of the evidence accumulation process depends on the relationship between changes in the LDP amplitude and changes in RTs. Past studies have interpreted a reduction in LPD amplitude, which is accompanied by an increase in RTs, as an accumulator having a reduced accumulation rate (Mangun and Buck, 1998; Itthipuripat et al., 2014a, 2017; Twomey et al., 2015). Accordingly, we expected that dividing attention should first lead to a decrease in SSVEP amplitude, and that this decrease in SSVEP amplitude should in turn lead to a reduction in the rate of evidence accumulation, a lower LPD amplitude, and increased RTs (see Fig. 2). If having more choices impacts sensory and decision-related processes in the same way as dividing attention, increasing the number of choices should also leads to a similar constellation of effects: smaller SSVEP amplitude, smaller LPD amplitude, and longer RTs (Fig. $2 a-c)$. However, if having more choices increases RTs because of higher decision thresholds and thus more total evidence accumulation, we would expect no changes in SSVEP signals and an increase in LPD amplitude (see Fig. $2 d-f$ ). Consistent with the latter prediction, we found that, when task difficulty was under experimental control, having more choices did not alter SSVEP signals and it led to an elevation of the LPD. These results suggest that having more choices makes decisions slower by selectively increasing decision thresholds.

\section{Materials and Methods}

Subjects. Twenty and 10 neurologically healthy human observers (age range, 19-44 years) with normal or corrected-to-normal vision participated in the main EEG experiment (mean \pm SD age: $23.25 \pm 5.53$ years, 10 male, all right-handed) and the behavioral control experiment, respectively (mean \pm SD age: $20.20 \pm 1.813$ years, 5 male, all righthanded). They were recruited from the University of California-San Diego community. All subjects provided written informed consent as required by the local Institutional Review Board at University of California-San Diego (IRB\#110176). They were compensated for \$10 and \$15 per hour for participating in behavioral and EEG recording sessions, respectively.

Stimuli and tasks. Stimuli were controlled by a PC running Windows XP using MATLAB (The MathWorks) and the Psychophysics Toolbox (version 3.0.8) (Brainard, 1997; Pelli, 1997). Subjects were seated $60 \mathrm{~cm}$ from the CRT monitor (which had a gray background of $34.51 \mathrm{~cd} / \mathrm{m}^{2}$, $120 \mathrm{~Hz}$ refresh rate). All behavioral experiments were conducted in dark rooms in a quiet experimental area. All EEG experiments were conducted in a dark, sound-attenuated, and electromagnetically shielded room (ETS Lindgren).

EEG experiment. In the main EEG experiment, subjects performed either a 2-alternative forced choice (2AFC) or 4-alternative forced choice (4AFC) contrast discrimination task (Fig. 1). In both 2AFC and 4AFC tasks, each trial started with either a focused or a divided attention cue. The focused attention cue pointed to one of the four visual quadrants that contained a target stimulus, whereas the divided attention cue pointed to all four quadrants and a target stimulus was equally likely to appear in any of the four quadrants. At 400-600 ms after the cue onset, an array of four checkerboard wedge stimuli appeared for $1500 \mathrm{~ms}$ (the distances from the fixation to the inner and outer edges were 7.03 and 13.46 degrees visual angle, respectively; the two lateral edges were 79.44 degrees apart). The spatial frequency of the wedge (from the fovea and to peripheral segments) was adjusted to match the cortical magnification values measured in human primary visual cortex (Cowey and Rolls, 1974; Sereno et al., 1995; Engel et al., 1997; Duncan and Boynton, 2003). The pedestal contrast (or baseline contrast) of the target stimulus was pseudo-randomly drawn from 6 contrast levels: $0 \%, 3.75 \%, 7.5 \%, 15 \%$, $30 \%$, and $60 \%$ Michelson contrasts. These contrast values were com- puted based on the values of the black and white portions of the checkerboards (i.e., minimum and maximum luminance values, respectively) following this equation: $\left(I_{\max }-I_{\min }\right) /\left(I_{\max }+I_{\min }\right) \times 100$. According to this equation, the luminance of the background does not affect the Michelson contrast value. Moreover, we controlled the mean luminance between $I_{\max }$ and $I_{\min }$ for all pedestal contrast levels to match the mean luminance of the background. The target stimulus contained a contrast increment in one of the segments that formed that stimulus. The contrast increment appeared for the entire stimulus duration of $1500 \mathrm{~ms}$. In addition, three of the four stimuli were nontarget stimuli. For each nontarget stimulus, all of its segments had the same contrast value, independently and randomly drawn from one of the six values $(0 \%, 3.75 \%, 7.5 \%$, $15 \%, 30 \%$, and $60 \%$ Michelson contrasts).

We used a full range of pedestal contrast levels for the following reasons. First, a full range of contrasts was needed to measure stimulusevoked responses (i.e., SSVEPs) as a function of stimulus contrast, yielding contrast-response functions (CRFs). Moreover, in the divided attention condition, subjects did not have any knowledge about which of the four stimuli in the display contained the target stimulus. Their task was to attend to all four of the visual stimuli and then to discriminate which stimulus segment at the target location contained a slight contrast increment. In our current design, the pedestal contrast values of the target and nontarget stimuli were randomly drawn from a full range of contrast values, so subjects had to use top-down attention to monitor all stimuli to find the target stimulus. However, if we had used only one pedestal contrast level for all stimuli, subjects could have simply used a bottom-up attentional capture strategy to detect a contrast increment of the target that would be more salient than all other stimuli rendered at the same pedestal contrast. Randomizing the pedestal contrasts of all visual stimuli thus prevented subjects from using this bottom-up attentional strategy.

In the 2AFC task, subjects reported whether the foveal or the peripheral segment had the contrast increment (Fig. 1a, bottom). In the 4AFC task, a target stimulus was segmented into four parts (the most foveal, foveal, peripheral, the most peripheral) and subjects reported which of the four parts contained a contrast increment (Fig. 1b, bottom). In the 2AFC task, half of the subjects used the right index and pinky fingers for the foveal and peripheral targets, respectively. The other half used right middle and ring fingers for the foveal and peripheral targets, respectively. In the 4AFC task, all subjects used right index, middle, ring, and pinky fingers for the most foveal, foveal, peripheral, the most peripheral targets, respectively. At $300 \mathrm{~ms}$ after the stimulus offset, placeholders on both sides of the target segment that contained a contrast increment changed from black to blue, red, or yellow, informing subjects if their response was correct, incorrect, or too slow (slower than $1500 \mathrm{~ms}$ after stimulus onset). The feedback period was then followed by a $300-500 \mathrm{~ms}$ intertrial interval. Any jittered time variables were drawn from the uniform distributions. To simultaneously monitor SSVEPs evoked by individual stimuli, the visual stimuli on the upper left, upper right, lower left, lower right quadrants were flickered on-off at 30, 17.1, 20, and $24 \mathrm{~Hz}$, respectively.

On the first day, subjects participated in a $2.5 \mathrm{~h}$ behavioral training session where the method of constant stimuli was used to estimate contrast discrimination thresholds (or contrast increments required to maintain an accuracy level of $\sim 76 \%$ ) for each AFC task, each attention condition, and each pedestal contrast level. These thresholds were used on the first day of EEG recording. On each of the $4 \mathrm{~d}$ of the EEG experiment, subjects underwent three sessions of the 2AFC task and three sessions of the 4AFC task (with task order counterbalanced across subjects). Each experimental session contained 192 trials, which were broken up into 3 blocks, where all experimental conditions were counterbalanced: for the $2 \mathrm{AFC}$ task, 2 attention conditions $\times 4$ target locations $\times 6$ pedestal contrast levels of target $\times 2$ increment locations $\times 2$ repetitions; for the $4 \mathrm{AFC}$ task, 2 attention conditions $\times 4$ target locations $\times 6$ pedestal contrast levels of target $\times 4$ increment locations. Trial order was pseudo-randomized. The contrast threshold $(\Delta \mathrm{c})$ for each attention condition and each target pedestal contrast was adjusted after each experimental session (every 3 blocks) so that accuracy was maintained at $\sim 76 \%$ across all experimental conditions. Across $4 \mathrm{~d}$ of EEG recording, each 
subject performed 36 blocks of the $2 \mathrm{AFC}$ task and 36 blocks of the 4 AFC task (4608 trials in total).

Behavioral control experiment. In the main EEG experiment, the entire area of each wedge checkerboard stimulus was identical across the 2AFC and $4 \mathrm{AFC}$ tasks. Thus, the resolution of the contrast-increment segment stimulus in the 2AFC task (termed low-spatial-resolution 2AFC) was unavoidably lower than that in the 4AFC task (termed high-spatialresolution $4 \mathrm{AFC}$ ). We did this because we wanted to carefully control for the spatial extent of overall sensory inputs. To ensure that any behavioral difference across the 2AFC and 4AFC tasks in the main EEG experiment was due to the difference in the number of choices rather than the difference in spatial resolution of the target stimulus, we conducted an additional behavioral control experiment. In this experiment, there were three main experimental conditions. These included low-spatialresolution 2AFC (same as 2AFC in the main EEG experiment), highspatial-resolution 4AFC (same as 4AFC in the main EEG experiment), and the high-spatial-resolution 2AFC (a new condition). In the highspatial-resolution $2 \mathrm{AFC}$ condition, the spatial resolution of the contrastincrement segment was the same as the high-spatial-resolution 4AFC condition, but subjects had 2 choices instead of 4 choices. However, at the beginning of each high-spatial-resolution 2AFC block, subjects were informed that the increment contrast could appear only at one of the two foveal segments (foveal high-spatial-resolution 2AFC) or one of the two peripheral segments (peripheral high-spatial-resolution 2AFC). Task timing was identical to that in the main EEG experiment. The pedestal contrasts of these four stimuli in all attention, choice, and target resolution conditions were independently and pseudo-randomly drawn from 3 contrast levels: 5\%, 20\%, and 60\% Michelson contrasts. Here, we used 3 instead of 6 contrast levels to keep the experimental protocol approximately the same length given that the number of experimental manipulations (not including the contrast manipulation) in the behavioral control experiment was higher than that in the main EEG experiment. Subjects completed $3 \mathrm{~d}$ of this experiment. Each day contained 2 sessions of low-spatial-resolution 2AFC, 2 sessions of high-spatial-resolution 4AFC, 2 sessions of foveal high-spatial-resolution 2AFC, and 2 sessions of peripheral high-spatial-resolution 2AFC. Each session had 3 blocks and contrast thresholds were adjusted every 3 blocks to maintain accuracy at $\sim 76 \%$. Each block contained 64 trials, and the entire experiment across $3 \mathrm{~d}$ contained 4608 trials per participant. The order of these choice tasks was randomized within each individual participant.

Behavioral analyses: main EEG experiment. Contrast thresholds (i.e., contrast increment values averaged across sessions) and RTs on correct and incorrect trials were plotted as a function of pedestal contrasts separately for the focused attention and divided attention in the 2AFC and 4 AFC tasks. Here, the plot of contrast thresholds against pedestal contrasts is termed the threshold-versus-contrast (TvC) function. Repeatedmeasures ANOVAs were used to examine the effects of attention and the number of choices on contrast thresholds, RTs on correct trials, and RTs on incorrect trials.

In addition, the $\mathrm{TvC}$ plots were fit using a combination of $d^{\prime}$ and Naka-Rushton equations (see Eqs. 1-3 below). Following previous work, we assumed that behavioral contrast sensitivity $\left(d^{\prime}\right)$ was limited by the difference in neural responses evoked by pedestal and incremental stimuli $(\Delta R)$ divided by the magnitude of sensory noise $(\sigma)$ (Legge and Foley, 1980; Ross et al., 1993; Boynton et al., 1999; Gorea and Sagi, 2001; Huang and Dobkins, 2005; Pestilli et al., 2011; Hara and Gardner, 2014; Itthipuripat et al., 2014a, 2017; Itthipuripat and Serences, 2016) as follows:

$$
d^{\prime}=\frac{\Delta R(c)}{\sigma}=\frac{R(c)-R(\Delta c(c))}{\sigma}
$$

Here, $c$ is stimulus contrast and $\Delta c(c)$ is the contrast threshold (or contrast increment) at each contrast level that is required to maintain an accuracy level of $\sim 76 \%$. $R(c)$ is a hypothetical contrast response function derived from a Naka-Rushton equation as follows:

$$
R(c)=G_{r} \frac{c^{q}}{c^{q}+G_{c}^{q}}+b
$$

In this equation, $G_{r}$ is a multiplicative response gain factor that controls the vertical shift of the CRF, $G_{c}$ is a contrast gain factor that controls the horizontal shift of the CRF, $b$ is the response baseline offset, and $q$ is the exponent that controls the speed at which the CRF rises and reaches asymptote. With the combination of the $d^{\prime}$ and Naka-Rushton equations (Eqs. 1-2), the contrast threshold $(\Delta c)$ can be estimated based on the first derivative (i.e., slope) of the hypothetical CRF (Boynton et al., 1999) as follows:

$$
\Delta c(c)=\frac{\Delta R(c)}{\frac{d R}{d c}}
$$

Here, $d R / d c$ is the derivative of the underlying CRF. In the 2AFC task, $\Delta R$ and $\sigma$ were set to 1 to keep $d^{\prime}$ at $1(\sim 76 \%$ accuracy for $2 \mathrm{AFC}=\sim 1)$, which was possible because $G_{r}, \Delta R$, and $\sigma$ are codependent (i.e., they jointly control the vertical shift of the TvC function). Because $\sim 76 \%$ accuracy for $4 \mathrm{AFC}$ corresponds to a $d^{\prime}$ of $\sim 1.72, \Delta \mathrm{R}$ was set to 1.72 (Stanislaw and Todorov, 1999). For both tasks, $b$ was set to zero because changes in $b$ do not affect the slope of the TvC function. Last, we fit the TvC functions of individual attention and choice conditions with Equations 1-3 with MATLAB's fminsearch function (Nelder-Mead method; nonlinear least squares) with $G_{r}, G_{c}$ and $q$ as free parameters. We used 5 initial seed values for $G_{c}$ (i.e., $1 \%, 10 \%, 20 \%, 50 \%$, and $100 \%$ contrast) and 5 initial seed values for $G_{r}$ (i.e., 1, 10, 20, 50, and 100 in arbitrary units) and 5 initial seed values for $q$ (i.e., 1, 2, 3, 4, and 5). We then selected the best fit for each experimental condition. In addition, the fitting procedure was constrained so that $0 \%<G_{c}<100 \%$ contrast.

Behavioral control experiment. Repeated-measures ANOVAs were used to examine the effects of attention and the number of choices on contrast thresholds, RTs on correct trials, and RTs on incorrect trials. Post hoc paired $t$ tests were then used to compare the data between the low-spatial-resolution $2 \mathrm{AFC}$ and the high-spatial-resolution $4 \mathrm{AFC}$ conditions, between the high-spatial-resolution 2AFC and high-spatialresolution $4 \mathrm{AFC}$ conditions, and between the low-spatial-resolution 2AFC and high-spatial-resolution 2AFC conditions (two-tailed).

EEG data acquisition. We recorded EEG data using an ActiveTwo system (Biosemi Instrumentation) with 64 channels (sampling rate $=512$ $\mathrm{Hz}$ ) with two reference electrodes placed on the left and right mastoids. We monitored horizontal eye movements via a pair of external electrodes affixed near the outer canthi of the left and right eyes and monitored blinks and vertical eye movements via two pairs of external electrodes affixed above and below the left and right eyes. The EEG data were referenced online to the CMS-DRL electrode, and the data offset in all electrodes were maintained $<20 \mu \mathrm{V}$ (a standard criterion for this active electrode system).

EEG data preprocessing and analysis. We preprocessed EEG data using custom MATLAB scripts and EEGLab11.0.3.1b (Delorme and Makeig, 2004). First, we rereferenced the EEG data to the averaged data recorded from the left and right mastoid electrodes and applied $0.25 \mathrm{~Hz}$ high-pass and $55 \mathrm{~Hz}$ low-pass Butterworth filters (third order). Next, we segmented the continuous EEG data into epochs extending from $500 \mathrm{~ms}$ before to $3000 \mathrm{~ms}$ after cue onset. Then, we performed independent component analysis to remove prominent eye blinks (Makeig et al., 1996) and used threshold rejection and visual inspection to reject trials containing residual eye movements, muscle activity, drifts, and other artifacts. This resulted in the removal of $10.08 \pm 5.25 \%$ SD of trials across all 20 subjects. Last, we time-locked the data to stimulus onset and removed the baseline activity from 0 to $100 \mathrm{~ms}$ before the stimulus onset.

SSVEP analysis. First, the stimulus-locked data were sorted into the following experimental bins: (1) 2AFC: focused attention target stimuli; (2) 2AFC: focused attention nontarget stimuli (e.g., ignored stimuli); (3) 2AFC: divided attention stimuli; (4) 4AFC: focused attention target stimuli; (5) 4AFC: focused attention nontarget stimuli (e.g., ignored stimuli); and (6) 4AFC: divided attention stimuli.

For each of these bins, trials were also sorted into 24 sub-bins depending on the contrast and the location of the stimulus of interest $(6$ contrast levels $\times 4$ stimulus locations). Next, we averaged the EEG data in all sub-bins to obtain event-related potentials (ERPs) for each condition. 
Then, we filtered the data with a Gaussian wavelet function with a 0.1 fractional bandwidth to obtain frequency-domain coefficients from 1 to $55 \mathrm{~Hz}$ in $1 \mathrm{~Hz}$ steps (except at $17.1 \mathrm{~Hz}$ where we use the exact stimulus driving frequency as the center frequency). SSVEPs evoked by individual stimulus flicker frequencies $(17.1,20,24$, and $30 \mathrm{~Hz})$ were obtained by computing the absolute value of the coefficients at the center flicker frequencies. Next, we rescaled the data for individual frequencies using the unity-based normalization method: $\left(\right.$ data - data $\left._{\min }\right) /\left(\right.$ data $_{\max }-$ data $\left._{\text {min }}\right)$ (Aksoy and Haralick, 2001) and averaged the rescaled data from the contralateral occipital electrode where the SSVEP signal peaked across all four center frequencies (O2 and $\mathrm{O} 1$ for left and right stimuli, respectively). Here, "contralateral" means contralateral to the visual stimulus of interest (either target or nontarget). For each subject and each experimental condition (focused attention, divided attention, and ignored stimuli in $2 \mathrm{AFC}$ and $4 \mathrm{AFC}$ tasks), the normalized SSVEPs were averaged across a $0-800 \mathrm{~ms}$ window and plotted as a function of stimulus contrast yielding SSVEP-based CRFs. Because mean RTs were $\sim 800-900$ $\mathrm{ms}$ across conditions, we used a $0-800 \mathrm{~ms}$ window to minimize potential confounds from including data after a response had been made. On the $x$-axis of the CRFs, the stimulus contrast values for the ignored stimulus were fixed at $0 \%, 3.75 \%, 7.5 \%, 15 \%, 30 \%$, and $60 \%$ Michelson contrasts. However, because the target stimuli contained both pedestal and increment segments, we used the average contrast values between the pedestal and increment segments for plotting the CRFs in the focused and divided attention conditions. The within-subject standard error of means (SEM) of the data for each contrast level was calculated using the approach described by Loftus and Masson (1994), in which the mean value between attention and choice conditions was removed from individual data before computing SEM for each contrast value.

Next, SSVEP-based CRFs for each attention and choice conditions of individual subjects were fit using the Naka-Rushton equation (Eq. 2), where $R(c)$ is the normalized SSVEP amplitude as a function of stimulus contrast (SSVEP-based CRFs). The $q$ exponent was fixed at 2 following previous studies (Herrmann et al., 2010; Carandini and Heeger, 2011; Itthipuripat et al., 2014b). Given that past EEG studies of spatial attention have consistently reported no changes in response baseline of CRFs based on sensory-evoked responses recorded using EEG (Di Russo et al., 2001; Kim et al., 2007, 2011; Lauritzen et al., 2010; Wang and Wade, 2011; Itthipuripat et al., 2014a,b, 2017), $b$ was fixed as the mean of the minimum values of the CRFs across all individual attention and choice conditions. We used 5 initial seed values for $G_{c}$ (i.e., $1 \%, 10 \%, 20 \%, 50 \%$, and $100 \%$ contrast) and 5 initial seed values for $G_{r}$ (i.e., the difference between maximum and minimum responses divided by $0.5,1,2,4$, and 8 ). For, each participant, we selected the seed values for $G_{c}$ and $G_{r}$ that yielded the best fit. In addition, the fitting procedure was constrained so that $0 \%<G_{c}<100 \%$ contrast. We then used a least square error estimation method (fminsearch function in MATLAB) to estimate the maximum response or $R_{\max }$ (the response at $100 \%$ contrast minus baseline), the half-maximum contrast or $C_{50}$ (contrast at which the response reached half-maximum). Next, we used repeated-measures ANOVAs to test effects of attention and the number of choices on the $R_{\max }$ and $C_{50}$ parameters.

ERP analysis. We obtained the LPD from the central frontal electrode (Fpz) where its mean amplitude averaged across all experimental conditions was maximal. Previous studies found that the LPD component emerged $\sim 400-800 \mathrm{~ms}$ after stimulus (Cravo et al., 2013; Kelly and O'Connell, 2013; Itthipuripat et al., 2015; Twomey et al., 2015; Nelli et al., 2017; Rungratsameetaweemana et al., 2018). Accordingly, we averaged the LPD amplitude across this time window and performed a repeatedmeasures ANOVA to test attention and choice effects and their interaction. This time window happened before the time of mean RTs ( $~ 800-900 \mathrm{~ms}$ after stimulus); therefore, the selection of this window also minimized confounds from postdecision data. Here we did not present attention and choice effects for each contrast level because there were no interactions between contrast and any of the attention and choice factors.

We also obtained the sustained negative-going potential from the posterior-occipital electrode contralateral to the focused and divided target stimuli (PO4 and PO3 for left and right targets, respectively; where the signal collapsed across all experimental conditions was maximal). Here, "contralateral" means contralateral to the target stimulus. We performed a repeated-measures ANOVA on the mean amplitude averaged from 400 to $800 \mathrm{~ms}$. The selection of time window was based on the timing of the similar ERP component observed in previous studies (Woodman et al., 2009; Kuo et al., 2012; Tsubomi et al., 2013) and based on the time of mean RTs to minimize confounds from postdecision data.

\section{Results}

Our main goal was to isolate the effects of changes in the number of available choices from changes in the number of sensory inputs, changes in the distribution of selective attention, and changes in task difficulty. We used the SSVEP-based CRF and the LPD component as neural markers of sensory and postsensory decision-related processes, respectively. If having more choices slows decision-making by reducing sensory responses, much like divided attention does (Mangun and Hillyard, 1987, 1988; Mangun and Buck, 1998; McMains and Somers, 2004; Toffanin et al., 2009; Pestilli et al., 2011; Hara and Gardner, 2014; Itthipuripat et al., 2014a, 2017; Wyart et al., 2015; Mayo and Maunsell, 2016), we expect to see dampened SSVEP responses over visual cortex and a reduction in LPD amplitude (Fig. $2 a-c$ ). However, if having more choices slows down decision-making by increasing the total amount of sensory evidence required before committing to a decision, we expect to see little impact on SSVEP amplitude and an increase in LPD amplitude (consistent with an elevated decision threshold; Fig. $2 d-f$ ).

In the present study, we used the contrast discrimination task for several reasons. First, contrast-change detection/discrimination is a good model task to examine perceptual decision-making processes because changes in contrast impact the efficiency of perceptual decisions about the orientation, color, motion, form, identity, and semantic properties of visual stimuli (Albrecht and Hamilton, 1982; Hawken et al., 1994; Alitto and Usrey, 2004; Murray and He, 2006; Herrmann et al., 2010, 2012; Purcell et al., 2010; Lui et al., 2013; Khayat and Martinez-Trujillo, 2015; Long et al., 2015; Khastkhodaei et al., 2016; Störmer and Alvarez, 2016; Wang and Movshon, 2016; Bloem and Ling, 2017; Hermes et al., 2017; Kay and Yeatman, 2017). Second, manipulating contrast enables precise control over task difficulty and other cognitive factors, such as spatial attention (Ross et al., 1993; Boynton et al., 1999; Gorea and Sagi, 2001; Huang and Dobkins, 2005; Pestilli et al., 2011; Hara and Gardner, 2014; Itthipuripat et al., 2014a, 2017). Third, previous studies have consistently found attentional modulations of early visual EEG responses (e.g., SSVEP and the P1 ERP component) using variants of contrast detection/ discrimination tasks (Johannes et al., 1995; Di Russo et al., 2001; Kim et al., 2007; Lauritzen et al., 2010; Wang and Wade, 2011; Itthipuripat et al., 2014a, b, 2017). This enabled us to use SSVEP as a well-vetted EEG marker of early sensory processing to examine the impact of selective attention and the number of available options on information processing. Third, a well-established theoretical framework based on studies of contrast perception allowed us to apply quantitative methods to fit psychophysical data and sensory responses (see Materials and Methods; Eqs. 1-3) (Boynton et al., 1999; Pestilli et al., 2011; Hara and Gardner, 2014; Itthipuripat et al., 2014a, 2017; Ku and van Schouwenburg, 2015; Itthipuripat and Serences, 2016). Last, the LPD component has been widely used to track the accumulation of sensory evidence in many studies that use contrast discrimination tasks as well as other perceptual decision-making tasks, including orientation, motion, color, object, face, and emotion discrimination tasks (O'Connell et al., 2012; Kelly and O'Connell, 2013; Murphy et al., 


\section{Alternative decison-making mechanisms \\ Predicted SSVEP amplitude}

a

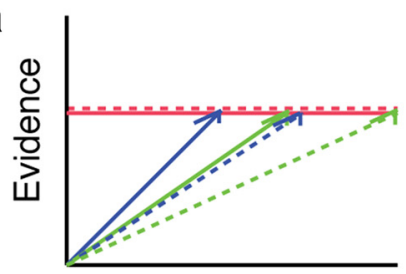

d

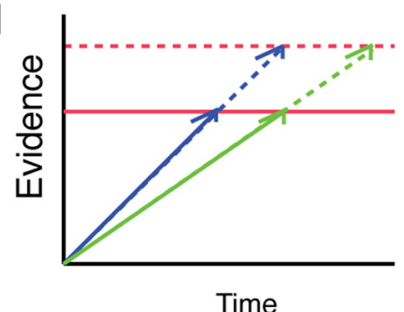

b

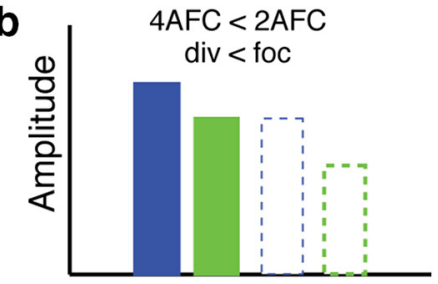

e

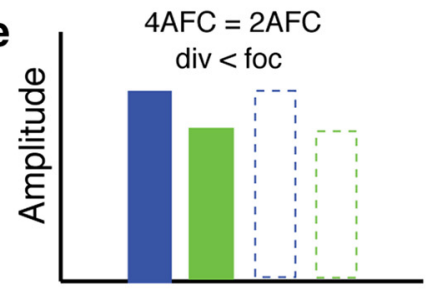

Time

\section{Predicted LPD amplitude}
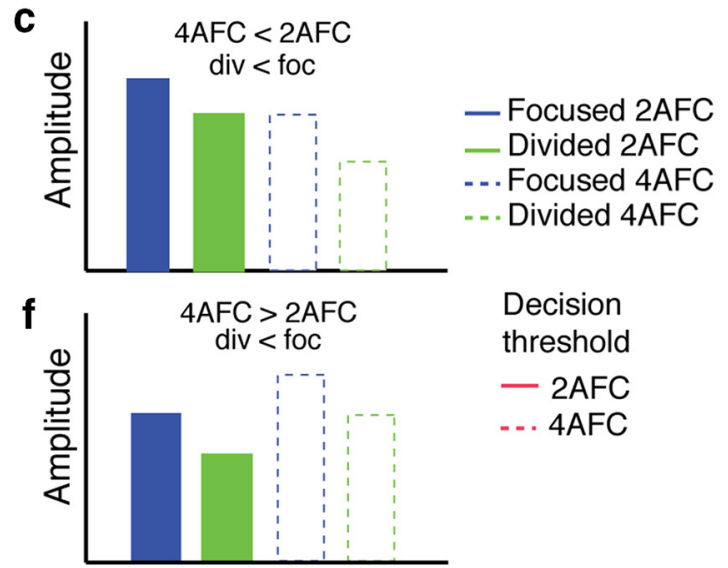

Time
Decision

threshold

- 2AFC

.. . 4AFC

Figure 2. Accumulate-to-bound accounts of the impact of attention and the number of choices on decision-making, along with corresponding predicted amplitudes of SSVEPs and the LPD. Here, we used SSVEPs to track the amplitude of early sensory signals and the LPD component to track the accumulation of sensory evidence during the buildup to a decision. If increasing the number of choices dampens sensory responses and decreases the rate of sensory evidence accumulation, as dividing attention does (a), SSVEP and LPD amplitudes should decrease and RTs should increase in response to both manipulations $(\boldsymbol{b}, \boldsymbol{c}$. However, if increasing the number of choices spares sensory modulations in visual cortex and increases RTs by elevating the decision threshold or the amount of accumulated evidence required before making a decision ( $\boldsymbol{d}$ ), there should instead be little or no modulation in SSVEP amplitude $(\boldsymbol{e})$ and a selective elevation of LPD amplitude accompanied by increased RTs $(\boldsymbol{f})$.

2015; Loughnane et al., 2016; Twomey et al., 2015, 2016; Newman et al., 2017; Sun et al., 2017; Rungratsameetaweemana et al., 2018).

\section{Behavioral results}

Main EEG experiment

Overall accuracy across attention conditions (focused/divided attention) and choice tasks (2AFC/4AFC) was successfully equated at $\sim 76 \%$ (Fig. $3 a$ ). Accordingly, there was no main effect on hit rates of attention $\left(F_{(1,19)}=1.63, p=0.2170\right)$ or the number of choices $\left(F_{(1,19)}=0.11, p=0.7488\right)$. Given that accuracy was fixed across conditions, we focused on the impact of attention and the number of choices on the contrast thresholds that were required to equate accuracy in each condition (Fig. $3 b$ ). The overall pattern of contrast threshold data in all experimental conditions was consistent with the typical shape of the TvC function, where contrast thresholds increase as a function of pedestal contrast with a slight dip between 0\% and medium contrast levels (Ross et al., 1993; Boynton et al., 1999; Huang and Dobkins, 2005; Pestilli et al., 2011). These data were well fit by a combination of $d^{\prime}$ and NakaRushton equations (Eqs. 1, 2; Fig. $3 d$, curve fits and $R^{2}$ values). This suggests that sensory responses increase as a function of stimulus contrast in a sublinear (sigmoid-like) fashion (see Fig. $7 a$, observed SSVEP-based CRF data). Importantly, we found that contrast thresholds were higher in the divided compared with the focused attention condition, consistent with previous studies $\left(F_{(1,19)}=76.28, p<0.001\right)$ (Pestilli et al., 2011; Hara and Gardner, 2014; Itthipuripat et al., 2014a, 2017). Contrast thresholds also increased as the number of choices increased $\left(F_{(1,19)}=\right.$ $70.18, p<0.001)$. There was no interaction between attention and the number of choices on contrast thresholds $\left(F_{(1,19)}=0.13\right.$, $p=0.7202$ ).

Attention and the number of choices also affected RTs (Fig. $3 c, d)$. On both correct and incorrect trials, RTs increased with divided attention compared with focused attention (correct RTs: $F_{(1,19)}=44.05, p<0.001$; incorrect RTs: $F_{(1,19)}=11.74, p=$
$0.0028)$. RTs also increased as the number of choices increased (correct RTs: $F_{(1,19)}=60.70, p<0.001$; incorrect RTs: $F_{(1,19)}=$ 72.96, $p<0.001)$. There was no interaction between attention and the number of alternative choices on RTs (correct RTs: $F_{(1,19)}=0.28, p=0.6020$; incorrect RTs: $F_{(1,19)}=0.02, p=$ $0.8842)$.

\section{Behavioral control experiment}

In the main experiment, we controlled the total area of the stimulus in each quadrant across the different choice tasks. However, the spatial resolution of the target in the $2 \mathrm{AFC}$ task was inevitably lower than that in the 4AFC task (Fig. $1 a, b$, bottom). Therefore, we conducted a behavioral control experiment to ensure that the observed differences in performance between the 2AFC and $4 \mathrm{AFC}$ conditions in the main task were not due to changes in the spatial resolution of the target. A separate set of 10 human subjects performed the main $2 \mathrm{AFC}$ and $4 \mathrm{AFC}$ tasks plus an additional 2AFC task in which the spatial resolution of the target matched the 4AFC task (i.e., high-spatial-resolution 2AFC). Replicating the main results reported above, contrast thresholds, correct RTs, and incorrect RTs were significantly higher in the 4AFC block compared with the 2AFC block (Fig. $4 ; t_{(9)}$ values $=6.26$, 3.04 , and 6.81, for contrast thresholds, correct RTs, and incorrect $\mathrm{RT}$, respectively; all $p$ values $<0.001)$. Importantly, these results held true, even when the spatial resolution of the target in the $4 \mathrm{AFC}$ and the 2AFC tasks was matched (high-spatial-resolution 2AFC vs high-spatial-resolution 4AFC: $t_{(9)}$ values $=6.26,3.04$, and 6.81 with $p<0.001, p=0.014$, and $p<0.001$ for contrast thresholds, correct RTs, and incorrect RTs, respectively). Importantly, we found no difference in contrast thresholds $\left(t_{(9)}=\right.$ $0.2829, p=0.7836)$, correct RTs $\left(t_{(9)}=1.66, p=0.1311\right)$, or incorrect RTs $\left(t_{(9)}=0.412, p=0.6849\right)$ between the lowresolution and the high-resolution versions of the $2 \mathrm{AFC}$ task. This control experiment suggests that a change in the spatial resolution of the targets across the $2 \mathrm{AFC}$ and $4 \mathrm{AFC}$ conditions 

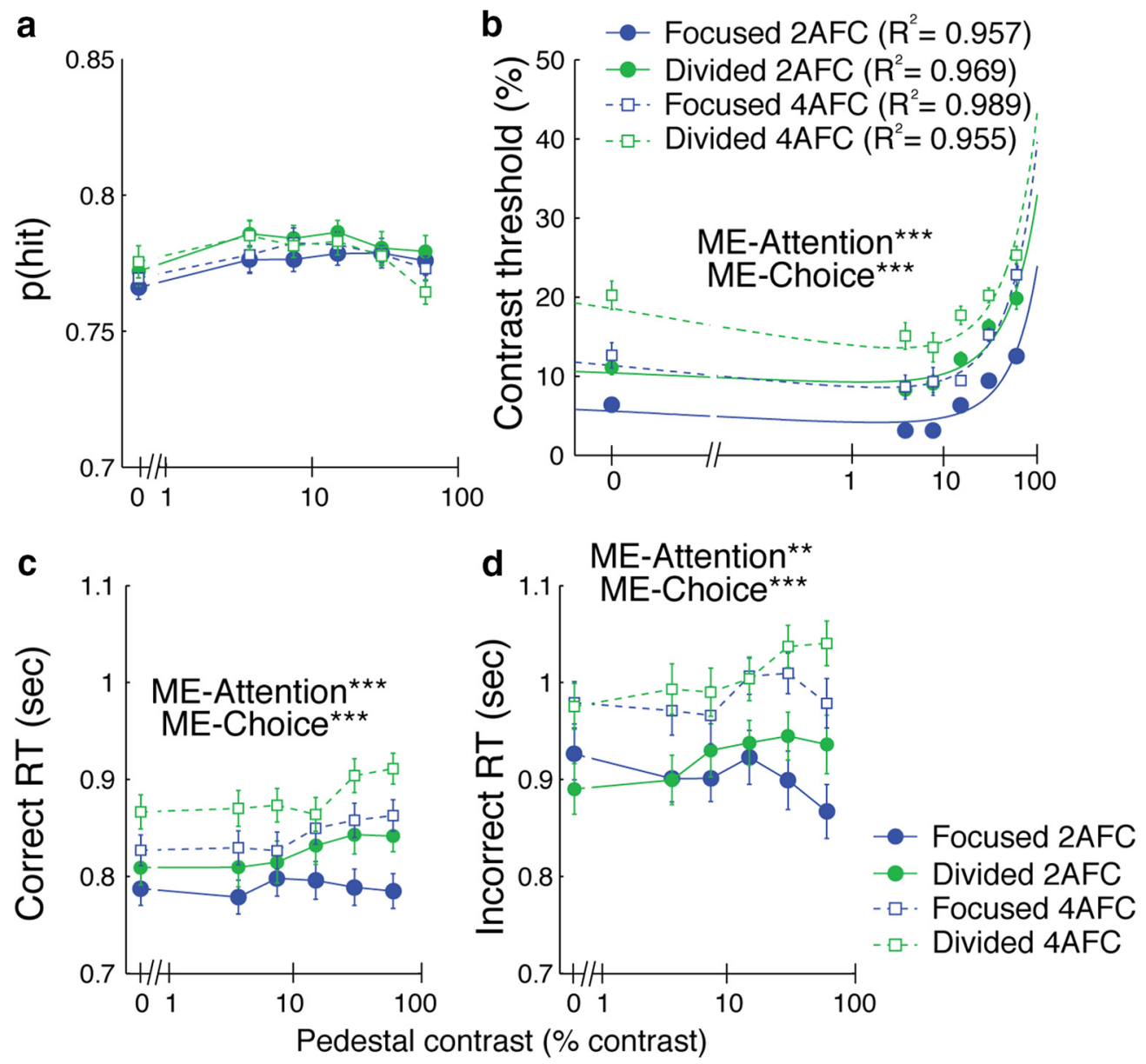

Figure 3. Behavioral results from the main EEG experiment. $\boldsymbol{a}$, Accuracy was equated at $\sim 76 \%$ across choice tasks, attention conditions, and contrast levels. $\boldsymbol{b}$, TvC functions. The data were fitted using a combination of Naka-Rushton and $d^{\prime}$ equations (Eqs. 1-3). There were significant main effects of the number of choices (ME-Choice) and attention (ME-Attention) on contrast threshold (b), RT on correct trials $(\boldsymbol{c})$, and RT on incorrect trials $(\boldsymbol{d})$. Error bars indicate within-subject SEM. ${ }^{* *} p<0.01,{ }^{* * *} p<0.001$.

was not a major contributor to the observed pattern of behavioral modulations in the main task.

\section{SSVEP results}

SSVEPs evoked by high-contrast stimuli were narrowly tuned to all four stimulation frequencies, and they peaked over contralateral occipital electrodes (Figs. 5, 6). As expected, the amplitudes of the SSVEPs differed substantially across different stimulus frequencies (Kim et al., 2011), so we rescaled the SSVEP data for each stimulus frequency using the unity-based normalization method (see Materials and Methods) (Aksoy and Haralick, 2001). Then, we collapsed the data across all stimulus frequencies. Next, we plotted the normalized SSVEPs (averaged over 0-800 ms after stimulus) from the contralateral occipital electrodes of interest to generate CRFs for individual attention and choice conditions (Fig. 7a). Because the time of mean RTs was at $\sim 800-900 \mathrm{~ms}$, we chose an analysis window of $0-800 \mathrm{~ms}$ to minimize confounds from postdecision data. Then, we fit each subject's CRFs with a Naka-Rushton equation (Eq. 2). This yielded two key parameters of interest: $R_{\max }$, which is the response at $100 \%$ contrast minus the baseline offset of the CRF (Fig. $7 b$, top); and the $C_{50}$, which shifts the CRF horizontally (Fig. $7 b$, bottom). Overall, the CRF data were well explained by the NakaRushton equation (Fig. $7 a$, curve fits and $R^{2}$ values).

Consistent with previous studies, there was a significant main effect of attention on $R_{\max }$, such that responses were highest in the focused attention condition and successively smaller in the divided attention and ignored conditions, respectively $\left(F_{(2,38)}=\right.$ 16.20, $p<0.001$ ) (Di Russo et al., 2001; Kim et al., 2007, 2011; Lauritzen et al., 2010; Wang and Wade, 2011; Itthipuripat et al., 2014a,b, 2017). In addition, due to the robust response gain changes with attention (i.e., $R_{\max }$ ), $C_{50}$ also increased in the focused compared with the divided and ignored conditions (i.e., contrast gain decreased, or the midpoint where the CRF reaches half of its maximal point shifted to the right, $F_{(2,38)}=10.87, p<$ $0.001)$. Interestingly, even though we observed significant differences in behavioral performance across the 2AFC and 4AFC tasks (Fig. 3), there was no significant main effect of the number of choices and no interaction between attention and the number of choices on $R_{\max }\left(F_{(1,19)}=0.73, p=0.4030\right.$, and $F_{(2,38)}=1.12, p=$ 0.3378 , respectively). Similarly, there was no main effect of the number of choices and no interaction between attention and the number of choices on $C_{50}\left(F_{(1,19)}=0.941 p=0.3442\right.$, and $F_{(2,38)}=2.04, p=0.1447$, respectively). The decrease in SSVEP signals with divided attention and no change in SSVEP signals with more choices are consistent with the prediction shown in Figure $2 e$.

\section{ERP results}

We observed a robust LPD component over frontal cortex that emerged at $\sim 400 \mathrm{~ms}$ and peaked around the time of mean RTs ( $\sim 800-900$ ms; Fig. 8a, left, $b$ ). Consistent with past studies, 

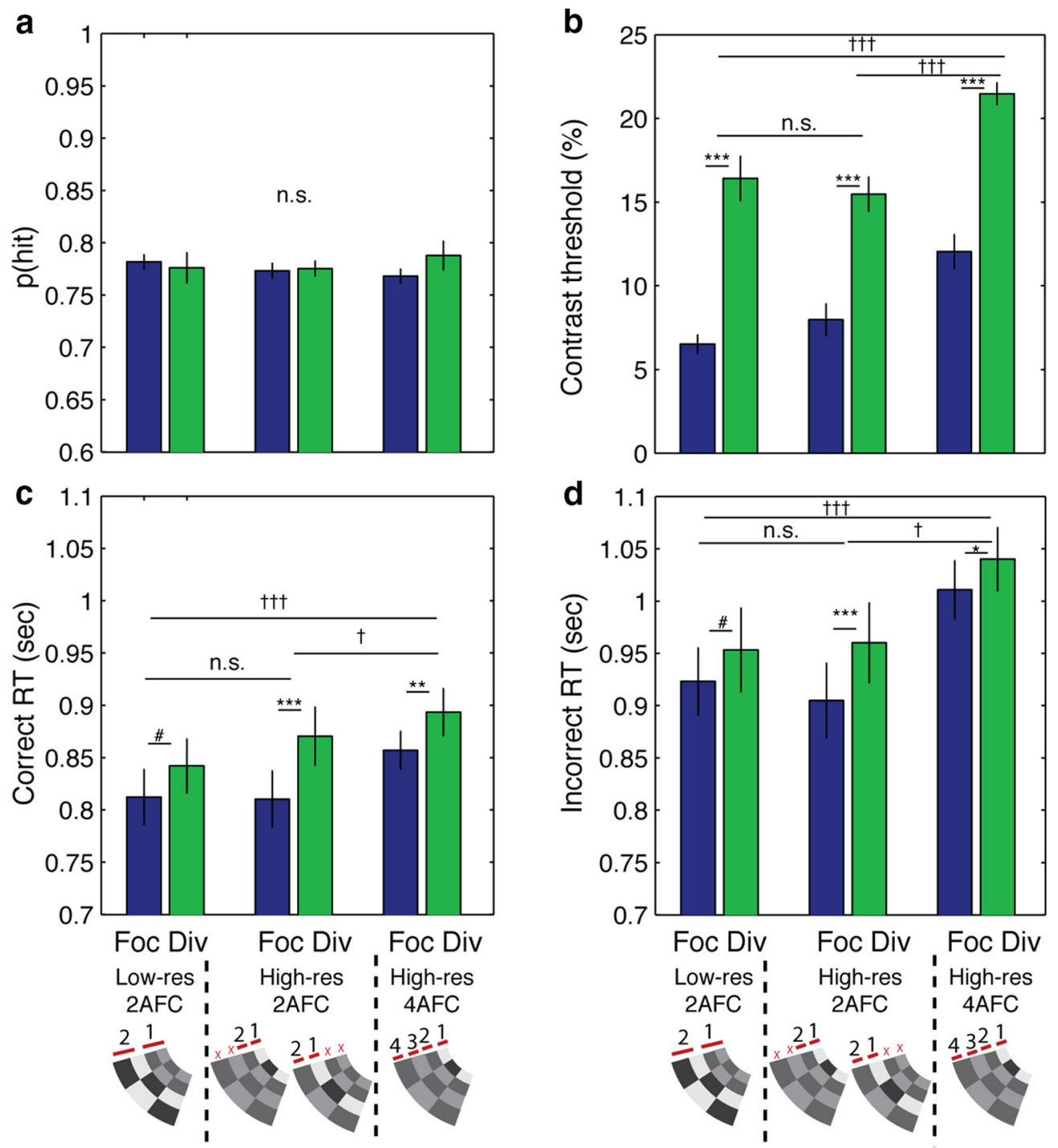

Figure 4. Behavioral results from the behavioral control experiment. In this experiment, there were three task conditions: 2AFC with low-spatial resolution targets (low-spatial-resolution 2AFC; same as 2AFC in the main EEG experiment), 2AFC with high-spatial-resolution targets (high-spatial-resolution 2AFC; an additional task), and 4AFC with high-spatial-resolution targets (high-spatial resolution $4 \mathrm{AFC}$; same as $4 \mathrm{AFC}$ in the main EEG experiment). $\boldsymbol{a}$, Hit rates were fixed at $\sim 0.76$ across all attention and task conditions. $\boldsymbol{b}$, Contrast discrimination thresholds. $\boldsymbol{c}$, RTs in correct trials. $\boldsymbol{d}$, RTs in incorrect trials. Overall, behavioral performance was impaired (i.e., thresholds and RTs increased) in the divided-attention compared with the focused-attention conditions and also in the 4AFC compared with the $2 \mathrm{AFC}$ tasks with low- and high-spatial-resolution targets. However, there was no difference in contrast thresholds or RTs between $2 \mathrm{AFC}$ tasks with low and high target resolution. This confirms that differences in behavioral performance observed across $2 A F C$ and $4 A F C$ tasks in Experiment 1 were due to the difference in number of choices rather than the difference in target spatial resolution. Error bars indicate the within-subject SEM across 10 subjects. Pairwise difference between attention conditions: ${ }^{\#} p<0.1,{ }^{*} p<0.05,{ }^{* *} p<0.01$, ${ }^{* * *} p<0.001$. Main effect of number of choices: ${ }^{\dagger} p<0.05,{ }^{+t+} p<0.001$.

dividing attention decreased the amplitude of the LPD component averaged over $400-800 \mathrm{~ms}\left(F_{(1,19)}=9.85, p=0.0054\right)$ (compare Mangun and Hillyard, 1988; Mangun and Buck, 1998; Itthipuripat et al., 2014a, 2017). However, while increasing the number of choices impaired behavioral performance in a manner similar to dividing attention (Fig. 3), we observed a significant elevation rather than a reduction in the amplitude of the LPD in the 4AFC compared with the $2 \mathrm{AFC}$ task $\left(F_{(1,19)}=6.00, p=\right.$ $0.0242)$. In addition, there was no interaction between attention and the number of choices on LPD amplitude $\left(F_{(1,19)}=1.1512\right.$, $p=0.2967)$.

Additionally, we found robust attention modulations of a slow-going late negativity over posterior-occipital cortex contralateral to the target stimulus (compare Woodman et al., 2009; Kuo et al., 2012; Tsubomi et al., 2013). Specifically, focused attention induced a more negative deflection from 400 to $800 \mathrm{~ms}$ after stimulus (Fig. $8 a$, right, $b ; F_{(1,19)}=44.51, p<0.0001$ ). We did not observe a significant main effect of the number of choice alternatives $\left(F_{(1,19)}=2.63, p=0.1211\right)$ or any interaction between attention and the number of choices $F_{(1,19)}$ values $=0.01$, $p=0.9068$ ). The pattern of this ERP data was similar to the SSVEP result, further supporting the idea that attention changes neural signals in occipital cortex, whereas the number of choices does not. Finally, the attentional modulation of the contralateral posterior-occipital negativity was very large, spreading over the posterior-central electrodes. Also, this negative ERP component and the LPD have opposite polarities. Because of the close proximity between posterior-central and posterior-occipital electrodes and the opposite polarities of the two ERP components, any expected modulations of the LPD in the posterior-central electrodes could be canceled out by changes in the contralateral posterior-occipital negativity (Luck, 2005; Woodman, 2010). 


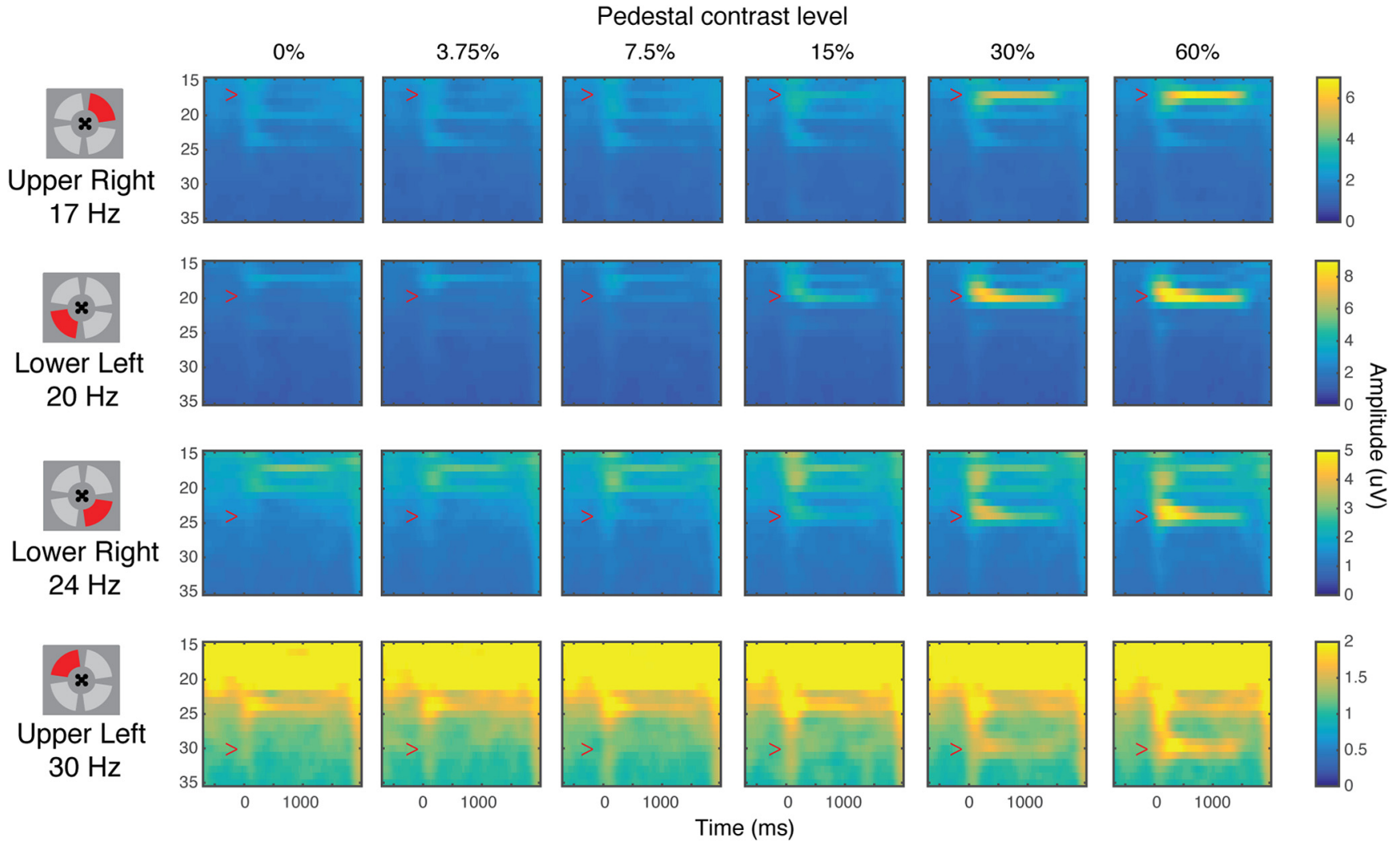

Figure 5. Time-frequency plots of evoked oscillatory responses elicited by visual stimuli of different contrast levels. The data were collapsed across attention and choice conditions and were obtained from contralateral occipital electrodes where SSVEPs peaked (01 and 02 for right and left quadrants, respectively). Overall, we observed SSVEPs evoked by high-contrast visual stimuli peaking at all four driving frequencies (red arrows) (see Fig. 6, corresponding topographical maps at the peak frequencies).

This may explain why significant differences in the LPD were observed primarily over frontal cortex, unlike some previous studies that observed robust differences in posterior-central electrodes (Mangun and Hillyard, 1988; Mangun and Buck, 1998; O'Connell et al., 2012; Kelly and O'Connell, 2013; Itthipuripat et al., 2014a, 2017, Twomey et al., 2015, 2016; Newman et al., 2017).

\section{Discussion}

Both dividing attention and having more choices made perceptual decisions slower and required higher perceptual thresholds to discriminate stimulus contrast with the fixed accuracy level of $\sim 76 \%$. Despite many superficial similarities between behavioral modulations associated with manipulating the distribution of spatial attention and increasing the number of choices, these two manipulations produced dissociable neural modulations of both early sensory and later decision-related processes. First, dividing attention decreased the SSVEP gain, but having more choices had no impact on SSVEPs. This suggests that having more options does not attenuate sensory responses, as long as changing the number of choices is not accompanied by a corresponding change in the number of competing sensory stimuli or task difficulty. Second, dividing attention decreased LPD amplitude, but having more options elevated LPD amplitude. This dissociation in the LPD response was observed, even though both manipulations led to a similar increase in overall RTs.

Longer RTs could be driven by a decrease in the rate of sensory accumulation or by an increase in the amount of evidence required before making a decision (i.e., an elevated decision threshold; Fig. 2a-f) (Gold and Shadlen, 2007; Brown and Heathcote, 2008). Dividing attention led to lower SSVEP responses and a lower-amplitude LPD. These findings are consistent with previous studies showing that divided or distributed attention reduces early sensory responses (Mangun and Buck, 1998; Pestilli et al., 2011; Itthipuripat et al., 2014a,b, 2017; Mayo and Maunsell, 2016) and the amplitude of the LPD (Mangun and Buck, 1998; Itthipuripat et al., 2014a, 2017). This latter result is consistent with a reduction in the rate of evidence accumulation or a leakier accumulation processes (Mangun and Buck, 1998; Itthipuripat et al., 2014a, 2017; Wyart et al., 2015). In contrast, the elevation of the LPD with an increase in the number of choices, particularly in the absence of SSVEP modulations, suggests an elevation of decision thresholds (Fig. $2 d-f$ ).

Here, the elevation of the LPD amplitude with more choices is inconsistent with previous reports suggesting that increasing the number of choices reduces, rather than elevates, neural activity in postsensory decision-related areas (Churchland et al., 2008; Cohen et al., 2009; Louie et al., 2011; Purcell et al., 2012). However, in these studies, the number of sensory inputs, the distribution of attention, and general task difficulty covary with the number of choices. For example, Churchland et al. (2008) increased the number of choices from two to four in a variant of the classic motion discrimination paradigm (Newsome et al., 1989; Shadlen and Newsome, 2001). In this task, different amounts of feature-based attention were required to monitor either two or four precued directions of motion (Churchland et al., 2008). Moreover, before the onset of motion, the subjects were cued with either two or four saccade targets, thus requiring different amounts of spatial attention. Here, task difficulty also increased markedly as indexed by a sharp decline in behavioral perfor- 


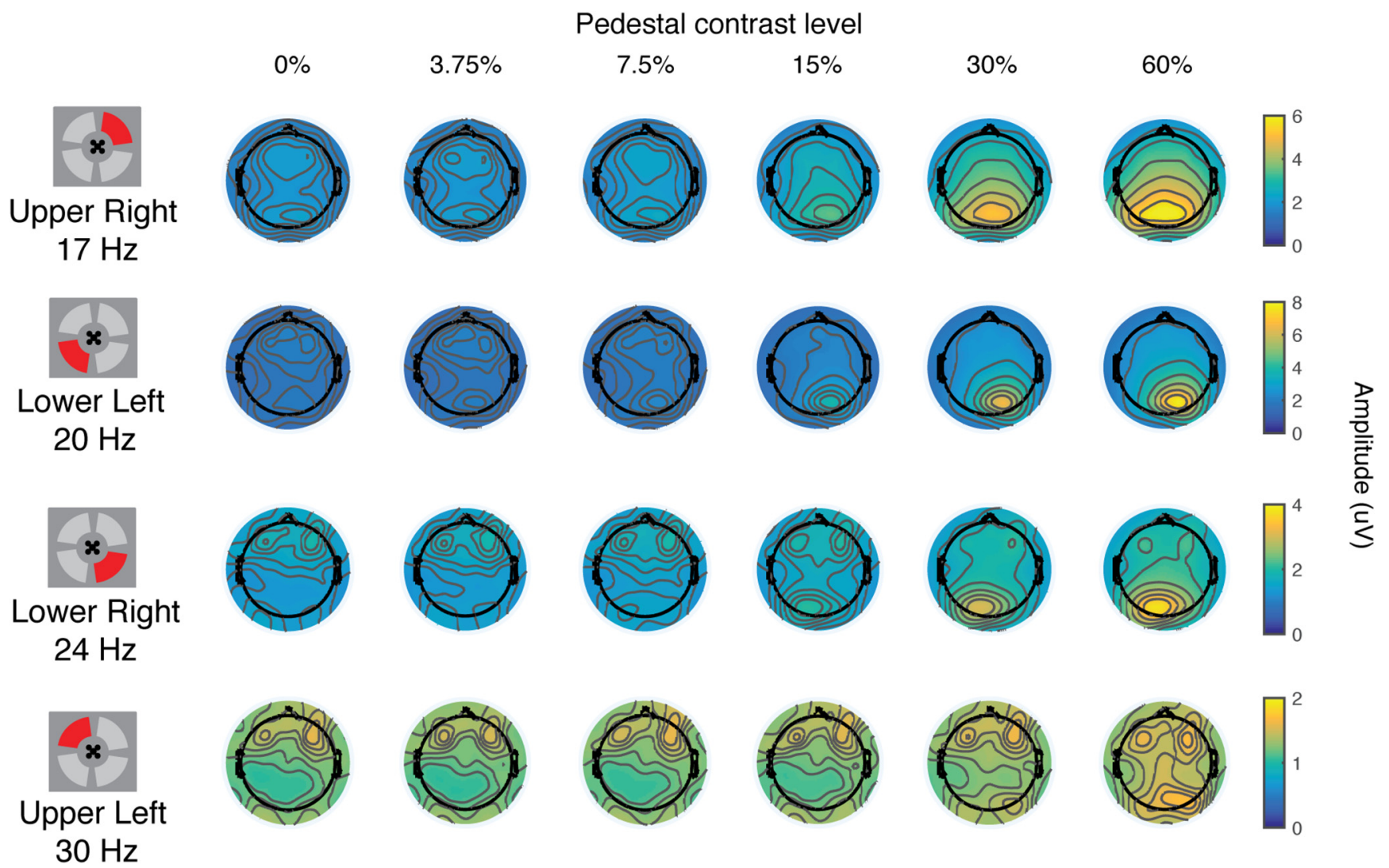

Figure 6. Topographical maps of SSVEP signals at the stimulus flicker frequencies shown in Figure 5. The data were collapsed across attention and choice conditions and were averaged over the entire stimulus period.

a

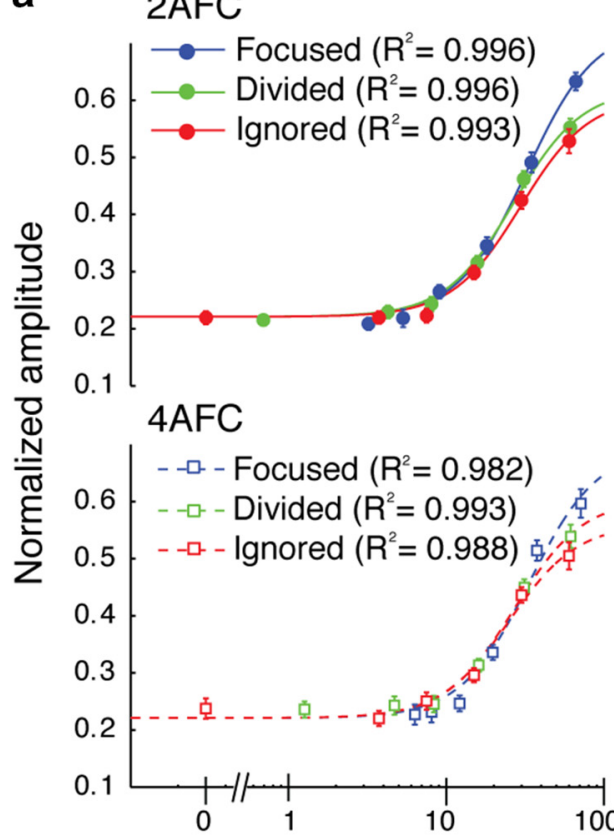

Focused
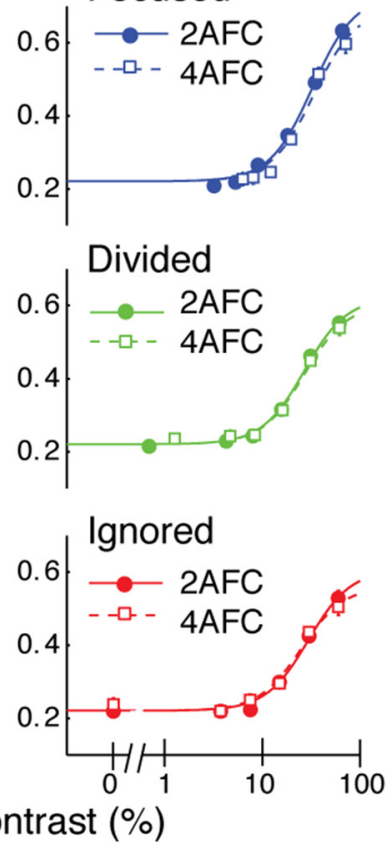

b
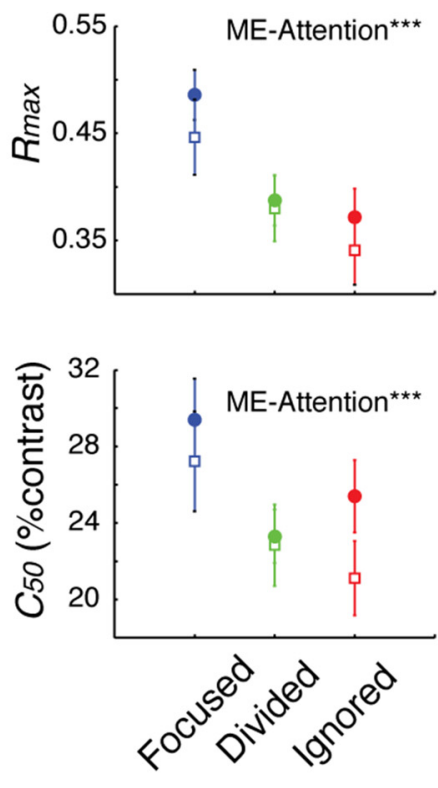

Figure 7. SSVEPs. $\boldsymbol{a}$, CRFs based on normalized SSVEPs evoked by focused attention, divided attention, and ignored stimuli across $2 A F C$ and $4 A F C$ tasks. The data were averaged over a time window extending from 0 to $800 \mathrm{~ms}$ after stimulus to minimize contributions after a behavioral response was made. The data were fit using a Naka-Rushton function (Eq. 2). $\boldsymbol{b}$, Fit parameters of the CRFs shown in $\boldsymbol{a}$. These include the maximum response $\left(R_{\text {max }} ;\right.$ top), which is the response at $100 \%$ contrast minus the baseline offset of the $\left(R F\right.$; and the semisaturation constant $\left(C_{50}\right.$; bottom), which shifts the CRF horizontally. Focused attention increased $R_{\max }$ and $C_{50}$ compared with divided attention and ignored conditions. However, there was no main effect of the number of choices on any of these CRF parameters. Error bars in all subfigures indicate within-subject SEM across 20 subjects. ${ }^{* * *}$ Significant main effects of attention $(p<0.001)$. 
a

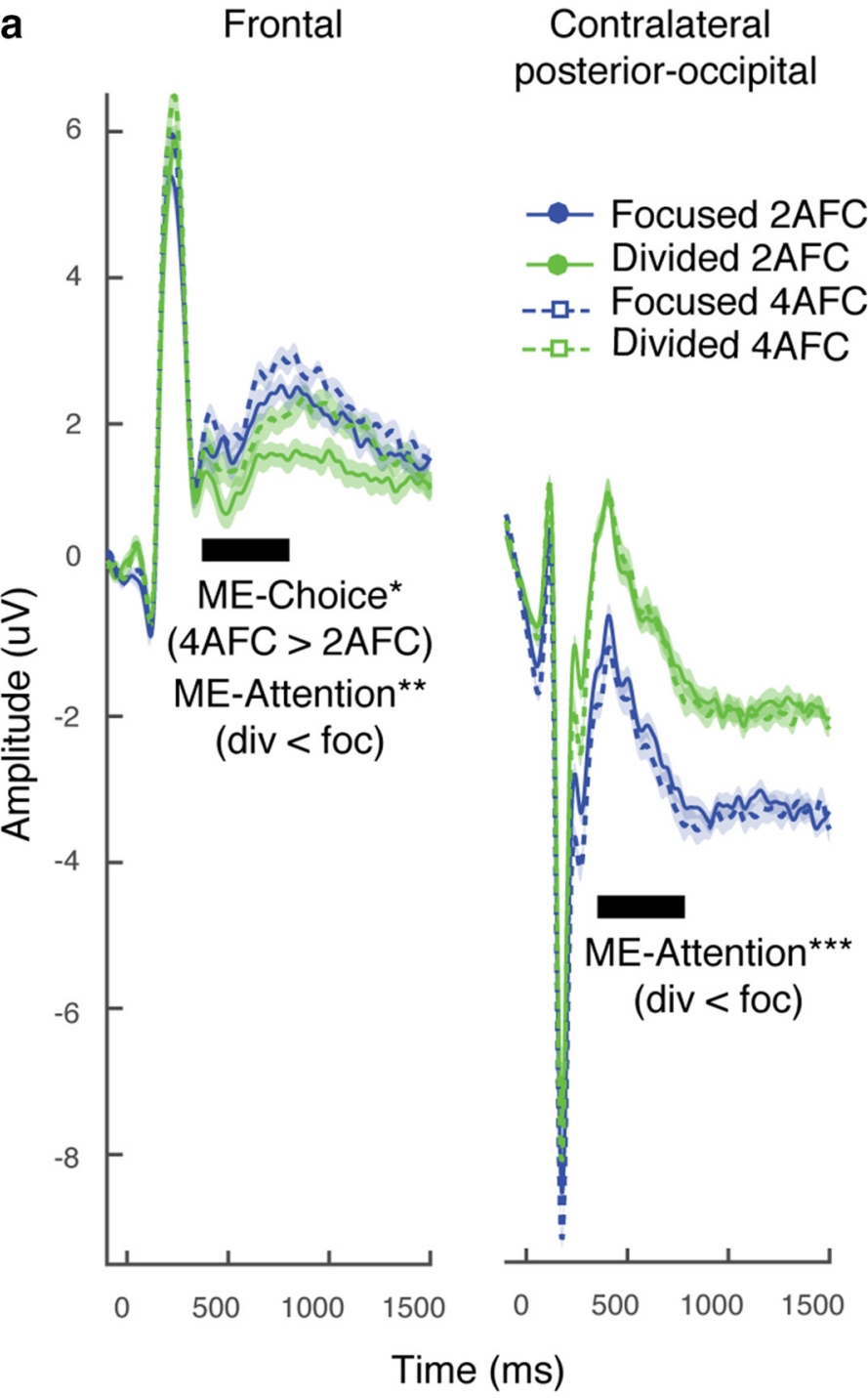

b

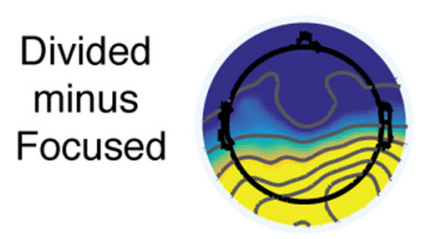

Figure 8. ERPs. $\boldsymbol{a}$, ERPs time-locked to stimulus onset in the midline frontal and contralateral posterior-occipital electrodes, respectively (data collapsed across all of the 6 target pedestal contrast levels). Black bars below the ERP traces represent the time windows where attention and choice modulations were tested ( $400-800 \mathrm{~ms})$. $\boldsymbol{b}$, Topographical maps showing ERP differences between divided and focused attention conditions and between $4 A F C$ and 2AFC tasks. Left and right sides of the topographical maps represent the ipsilateral and contralateral hemisphere, respectively, with respect to the target stimulus. Shading and error bars indicate within-subject SEM. ${ }^{*} p<0.05,{ }^{* *} p<0.01,{ }^{* * *} p<0.001$.

mance as the number of choices increased. Similarly, Purcell et al. (2012) manipulated the number of choices by adding more visual stimuli to the search arrays, thus increasing the distribution of spatial attention and task difficulty.

Consistent with the concern about potential confounds from task difficulty and attention, the firing rates of LIP and FEF neurons are reduced as task difficulty was increased, for example, by reducing the amount of sensory information available about an imperative stimulus (Gold and Shadlen, 2002, 2007; Roitman and Shadlen,

2002; Purcell et al., 2010, 2012). Past EEG studies have also shown that the LPD amplitude reduces with increasing task difficulty as well as decreasing the amount of sensory evidence (Hillyard et al., 1972; Squires et al., 1975; Mangun and Hillyard, 1988; O'Connell et al., 2012; Kelly and O'Connell, 2013; Itthipuripat et al., 2014a, 2017; Sun et al., 2017). Moreover, dividing attention across multiple sensory stimuli has been associated with a reduction in the level of neural responses in both early sensory and decision-related sensorimotor areas (Mangun and Hillyard, 1987, 1988; Palmer, 1994, 1995; Mangun and Buck, 1998; Awh and Pashler, 2000; Eckstein et al., 2000; McMains and Somers, 2004; Toffanin et al., 2009; Eckstein, 2011; Pestilli et al., 2011; Hara and Gardner, 2014; Itthipuripat et al., 2014a, 2017; Gardner, 2015; Wyart et al., 2015; Mayo and Maunsell, 2016). Thus, previous reports showing reduced neural activity with more choices in decision-related brain areas may be largely attributed to changes in the distribution of attention and task difficulty.

In many previous studies, increasing the number of choices was also accompanied by a concurrent increase in the spatial extent of the visual stimulus array. This could reduce neural activity via divisive normalization, a canonical neural computation observed in many sensory and postsensory areas along the visual hierarchy (Heeger, 1992; Zoccolan et al., 2005; Reynolds and Heeger, 2009; Sundberg et al., 2009; Carandini and Heeger, 2011; Louie et al., 2011, 2013; Reynaud et al., 2012; Chau et al., 2014; Itthipuripat et al., 2014b, 2015; Zhang et al., 2016). Based on divisive normalization, the output from a given neuron is a product of the excitatory activity divided by the suppressive drive pooled from surrounding neurons (Heeger, 1992; Reynolds and Heeger, 2009; Carandini and Heeger, 2011). Thus, in some displays where more stimuli occupy a larger proportion of the display, competition between the stimuli will increase and overall suppressive drive will increase. In turn, increases in suppressive drive will lead to an overall reduction in neural responses. Thus, in studies where the spatial extent of visual stimuli increases with the number of choices, reduced neural responses might not be induced by having more options per se but instead by increasing the spatial extent of the visual stimuli, which drives changes in divisive normalization (e.g., Purcell et al., 2012; Chau et al., 2014; Keuken et al., 2015). The main result from our study suggests that this is a plausible account of some previous findings because, when we equated the spatial extent of visual stimuli across 2AFC and 4AFC tasks, we observed no change in SSVEP signals and an elevation instead of a reduction of the LPD amplitude. 
Many previous decision-making experiments explicitly model the behavioral data using variants of an accumulate-to-bound model (e.g., Churchland et al., 2008; Purcell et al., 2012). However, the present study controlled difficulty across experimental conditions and is thus not amenable to fitting with this family of models as different accuracy levels, and RT distributions are required to dissociate changes in different model parameters. Subjects in the present task had to discriminate a contrast difference across spatial locations while we adjusted contrast increments (or $\Delta$ c) to maintain a fixed accuracy level of $\sim 76 \%$ across all experimental conditions. Thus, subjects had to accumulate evidence about $\Delta c$ across time. While $\Delta c$ varied across different pedestal contrast levels, the amount of sensory evidence available to support decision-making was fixed. As a result, there were no RT differences across contrast levels (or accuracy differences), and using a formal accumulate-to-bound model would not yield further insights because parameters, such as the drift rate, would be the same across conditions. That said, we did observe clear evidence showing that attention and choice modulations have dissociable effects on the LPD component, which has been consistently shown to track evidence accumulation processes (O'Connell et al., 2012; Kelly and O'Connell, 2013; Twomey et al., 2015; Loughnane et al., 2016; Rungratsameetaweemana et al., 2018). Thus, even though formal modeling might not reveal any interesting differences between model parameters because we controlled accuracy across conditions, our task still likely involves the same types of information processing mechanisms that have been previously discussed in the literature.

Finally, it is possible that the discrepancies between the results from our LPD data and single-unit data in LIP and FEF reported by previous studies could be due to the diffuse nature of EEG signals (Churchland et al., 2008; Purcell et al., 2012). That said, the LPD component is a well-validated marker of decisionmaking processes, as it tracks sensory evidence accumulation in a similar fashion as ramping activity in LIP and FEF neurons (O'Connell et al., 2012; Kelly and O'Connell, 2013; Twomey et al., 2015; Loughnane et al., 2016; Rungratsameetaweemana et al., 2018). Moreover, in the present study, we showed that the LPD component was a sensitive measure that was modulated by both changes in the distribution of attention and the number of choices. Finally, the observation that these two cognitive factors have opposing effects on LPD amplitude was not due to the differential effects in behavioral data as both dividing attention and increasing the number of choices increased contrast thresholds and mean RTs by a similar amount.

So far, empirical studies investigating the influence of choices on perceptual decision-making processes have only used simple visual stimuli (e.g., Balan et al., 2008; Churchland et al., 2008; Cohen et al., 2009; Purcell et al., 2012), whereas decision-making in real life involves more complex stimuli (e.g., selecting a meal from the menu or buying a shirt from the department store). Here, we argue that perceptual decision-making is a good, albeit simplified, model for many other general decision-making processes because, in almost all types of decision-making, one has to ponder some form of sensory evidence and use that evidence to make a decision. For example, while selecting a meal from the menu, one could sit at the restaurant for an hour pondering how the combined sensory experience of all the ingredients will taste before deciding what to eat. This will likely yield a reasonable decision and hopefully an enjoyable meal. However, one could also just base their decision on the anticipated flavor of the first ingredient and not ponder how all the sensory experiences induced by different ingredients will interact. In this case, the deci- sion will be fast but far more likely to end in an unpleasant experience. That said, there is no doubt that our paradigm is a simplified model for these more complex scenarios, and future experiments with more real-world stimuli will be needed to augment the present results.

Overall, our results suggest that previously reported reductions in neural activity and in accumulation rates in frontal and parietal cortex may be a result of increases in the distribution of attention and changes in task difficulty. Importantly, when these factors were controlled, increasing the number of choices selectively increases decision-related responses over frontal cortex and does not modulate sensory responses over occipital cortex. Together, this pattern suggests that having more choices changes the way human observers weight otherwise stable sensory evidence, and this leads to elevated decision thresholds and slower decision-making.

\section{References}

Aksoy S, Haralick RM (2001) Feature normalization and likelihood-based similarity measures for image retrieval. Pattern Recognit Lett 22:563-582. CrossRef

Albantakis L, Deco G (2009) The encoding of alternatives in multiplechoice decision making. Proc Natl Acad Sci U S A 106:10308-10313. CrossRef Medline

Albrecht DG, Hamilton DB (1982) Striate cortex of monkey and cat: contrast response function. J Neurophysiol 48:217-237. CrossRef Medline

Alitto HJ, Usrey WM (2004) Ferret primary visual cortex. J Neurophysiol 91:2797-2808. CrossRef Medline

Andersen SK, Müller MM (2010) Behavioral performance follows the time course of neural facilitation and suppression during cued shifts of featureselective attention. Proc Natl Acad Sci U S A 107:13878-13882. CrossRef Medline

Arcizet F, Mirpour K, Foster DJ, Bisley JW (2017) Activity in LIP, but not V4, matches performance when attention is spread. Cereb Cortex 23:115. CrossRef Medline

Awh E, Pashler H (2000) Evidence for split attentional foci. J Exp Psychol Hum Percept Perform 26:834-846. CrossRef Medline

Balan PF, Oristaglio J, Schneider DM, Gottlieb J (2008) Neuronal correlates of the set-size effect in monkey lateral intraparietal area. PLoS Biol 6:e158. CrossRef Medline

Banca P, Vestergaard MD, Rankov V, Baek K, Mitchell S, Lapa T, CasteloBranco M, Voon V (2015) Evidence accumulation in obsessivecompulsive disorder: the role of uncertainty and monetary reward on perceptual decision-making thresholds, Neuropsychopharmacology 40: 1192-1202. CrossRef

Bloem IM, Ling S (2017) Attentional modulation interacts with orientation anisotropies in contrast perception. J Vis 17:6. CrossRef Medline

Bogacz R, Usher M, Zhang J, McClelland JL (2007) Extending a biologically inspired model of choice: multi-alternatives, nonlinearity, and valuebased multidimensional choice. Philos Trans R Soc Lond B Biol Sci 362: 1655-1670. CrossRef Medline

Boynton GM, Demb JB, Glover GH, Heeger DJ (1999) Neuronal basis of contrast discrimination. Vision Res 39:257-269. CrossRef Medline

Brainard DH (1997) The psychophysics toolbox. Spat Vis 10:433-436. CrossRef Medline

Brown SD, Heathcote A (2008) The simplest complete model of choice response time: linear ballistic accumulation. Cogn Psychol 57:153-178. CrossRef Medline

Busemeyer JR, Townsend J (1993) Decision field theory: a dynamiccognitive approach to decision making in an uncertain environment. Psychol Rev 100:422-459. Medline

Carandini M, Heeger DJ (2011) Normalization as a canonical neural computation. Nat Rev Neurosci 13:51-62. CrossRef Medline

Chau BK, Kolling N, Hunt LT, Walton ME, Rushworth MF (2014) A neural mechanism underlying failure of optimal choice with multiple alternatives. Nat Neurosci 17:463-470. CrossRef Medline

Churchland AK, Ditterich J (2012) New advances in understanding decisions among multiple alternatives. Curr Opin Neurobiol 22:920-926. CrossRef Medline 
Churchland AK, Kiani R, Shadlen MN (2008) Decision-making with multiple alternatives. Nat Neurosci 11:693-702. CrossRef Medline

Cohen JY, Heitz RP, Woodman GF, Schall JD (2009) Neural basis of the set-size effect in frontal eye field: timing of attention during visual search. J Neurophysiol 101:1699-1704. CrossRef Medline

Cowey A, Rolls ET (1974) Human cortical magnification factor and its relation to visual acuity. Exp Brain Res 21:447-454. Medline

Cravo AM, Rohenkohl G, Wyart V, Nobre AC (2013) Temporal expectation enhances contrast sensitivity by phase entrainment of low-frequency oscillations in visual cortex. J Neurosci 33:4002-4010. CrossRef Medline

Delorme A, Makeig S (2004) EEGLAB: an open source toolbox for analysis of single-trial EEG dynamics including independent component analysis. J Neurosci Methods 134:9-21. CrossRef Medline

Di Russo F, Spinelli D, Morrone MC (2001) Automatic gain control contrast mechanisms are modulated by attention in humans: evidence from visual evoked potentials. Vision Res 41:2435-2447. CrossRef Medline

Duncan RO, Boynton GM (2003) Cortical magnification within human primary visual cortex correlates with acuity thresholds. Neuron 38:659671. CrossRef Medline

Eckstein MP (2011) Visual search: a retrospective. J Vis 11:14. CrossRef Medline

Eckstein MP, Thomas JP, Palmer J, Shimozaki SS (2000) A signal detection model predicts the effects of set size on visual search accuracy for feature, conjunction, triple conjunction, and disjunction displays. Percept Psychophys 62:425-451. CrossRef Medline

Engel SA, Glover GH, Wandell BA (1997) Retinotopic organization in human visual cortex and the spatial precision of functional MRI. Cereb Cortex 7:181-192. CrossRef Medline

Ester E, Ho T, Brown S, Serences J (2014) Variability in visual working memory ability limits the efficiency of perceptual decision making. J Vis 14:1-12. CrossRef Medline

Furman M, Wang XJ (2008) Similarity effect and optimal control of multiple-choice decision making. Neuron 60:1153-1168. CrossRef Medline

Gardner JL (2015) A case for human systems neuroscience. Neuroscience 296:130-137. CrossRef Medline

Gold JI, Shadlen MN (2002) Banburismus and the brain: decoding review the relationship between sensory stimuli, decisions, and reward. Neuron 36:299-308. CrossRef Medline

Gold JI, Shadlen MN (2007) The neural basis of decision making. Annu Rev Neurosci 30:535-574. CrossRef Medline

Gorea A, Sagi D (2001) Disentangling signal from noise in visual contrast discrimination. Nat Neurosci 4:1146-1150. CrossRef Medline

Hara Y, Gardner JL (2014) Encoding of graded changes in spatial specificity of prior cues in human visual cortex. J Neurophysiol 112:2834-2849. CrossRef Medline

Hawken MJ, Gegenfurtner KR, Tang C (1994) Contrast dependence of colour and luminance motion mechanisms in human vision. Nature 367: 268-270. CrossRef Medline

Heeger DJ (1992) Normalization of cell responses in cat striate cortex. Vis Neurosci 9:181-197. CrossRef Medline

Hermes D, Nguyen M, Winawer J (2017) Neuronal synchrony and the relation between the BOLD response and the local field potential. PLoS Biol 15:e2001461. CrossRef Medline

Herrmann K, Montaser-Kouhsari L, Carrasco M, Heeger DJ (2010) When size matters: attention affects performance by contrast or response gain. Nat Neurosci 13:1554-1559. CrossRef Medline

Herrmann K, Heeger DJ, Carrasco M (2012) Feature-based attention enhances performance by increasing response gain. Vision Res 74:10-20. CrossRef Medline

Hick WE (1952) On the rate of gain of information. Q J Exp Psychol (Hove) 4:11-26. CrossRef

Hillyard S, Squires K, Baue J, Lindsay P (1972) Evoked potential correlates of response criterion in auditory signal detection. Science 177:1357-1360. CrossRef Medline

Ho TC, Brown S, Abuyo NA, Ku EH, Serences JT (2012a) Perceptual consequences of feature-based attentional enhancement and suppression. J Vis 12:15. CrossRef Medline

Ho TC, Brown S, van Maanen L, Forstmann BU, Wagenmakers EJ, Serences JT (2012b) The optimality of sensory processing during the speedaccuracy tradeoff. J Neurosci 32:7992-8003. CrossRef Medline

Huang L, Dobkins KR (2005) Attentional effects on contrast discrimination in humans: evidence for both contrast gain and response gain. Vision Res 45:1201-1212. CrossRef Medline

Hyman R (1953) Stimulus information as determinant of reaction time. J Exp Psychol 45:188-196. CrossRef Medline

Itthipuripat S, Serences JT (2016) Integrating levels of analysis in systems and cognitive neurosciences: selective attention as a case study. Neuroscientist 22:225-237. CrossRef Medline

Itthipuripat S, Ester EF, Deering S, Serences JT (2014a) Sensory gain outperforms efficient readout mechanisms in predicting attention-related improvements in behavior. J Neurosci 34:13384-13398. CrossRef Medline

Itthipuripat S, Garcia JO, Rungratsameetaweemana N, Sprague TC, Serences JT (2014b) Changing the spatial scope of attention alters patterns of neural gain in human cortex. J Neurosci 34:112-123. CrossRef Medline

Itthipuripat S, Cha K, Rangsipat N, Serences JT (2015) Value-based attentional capture influences context-dependent decision-making. J Neurophysiol 114:560-569. CrossRef Medline

Itthipuripat S, Cha K, Byers A, Serences JT (2017) Two different mechanisms support selective attention at different phases of training. PLoS Biol 15:1-38. CrossRef Medline

Johannes S, Münte TF, Heinze HJ, Mangun GR (1995) Luminance and spatial attention effects on early visual processing. Cogn Brain Res 2:189205. CrossRef Medline

Kay KN, Yeatman JD (2017) Bottom-up and top-down computations in word- and face-selective cortex. Elife 6:1-29. CrossRef Medline

Kelly SP, O'Connell RG (2013) Internal and external influences on the rate of sensory evidence accumulation in the human brain. J Neurosci 33: 19434-19441. CrossRef Medline

Keuken MC, Van Maanen L, Bogacz R, Schäfer A, Neumann J, Turner R, Forstmann BU (2015) The subthalamic nucleus during decisionmaking with multiple alternatives. Hum Brain Mapp 36:4041-4052. CrossRef Medline

Khastkhodaei Z, Jurjut O, Katzner S, Busse L (2016) Mice can use secondorder, contrast-modulated stimuli to guide visual perception. J Neurosci 36:4457-4469. CrossRef Medline

Khayat PS, Martinez-Trujillo JC (2015) Effects of attention and distractor contrast on the responses of middle temporal area neurons to transient motion direction changes. Eur J Neurosci 41:1603-1613. CrossRef Medline

Kim YJ, Grabowecky M, Paller KA, Muthu K, Suzuki S (2007) Attention induces synchronization-based response gain in steady-state visual evoked potentials. Nat Neurosci 10:117-125. CrossRef Medline

Kim YJ, Grabowecky M, Paller KA, Suzuki S (2011) Differential roles of frequency-following and frequency-doubling visual responses revealed by evoked neural harmonics. J Cogn Neurosci 23:1875-1886. CrossRef Medline

Ku Y, van Schouwenburg MR (2015) Explaining attention-related changes in behavior and electroencephalography data through computational modeling. J Neurophysiol 114:2087-2089. CrossRef Medline

Kuo BC, Stokes MG, Nobre AC (2012) Attention modulates maintenance of representations in visual short-term memory. J Cogn Neurosci 24:51-60. CrossRef Medline

Laming DR (1968) Information theory of choice-reaction times. London: Academic.

Lauritzen TZ, Ales JM, Wade AR (2010) The effects of visuospatial attention measured across visual cortex using source-imaged, steady-state EEG. J Vis 10:39. CrossRef Medline

Legge GE, Foley JM (1980) Contrast masking in human vision. J Opt Soc Am 70:1458-1471. CrossRef Medline

Leite FP, Ratcliff R (2010) Modeling reaction time and accuracy of multiplealternative decisions. Atten Percept Psychophys 72:246-273. CrossRef Medline

Link SW, Heath RA (1975) A sequential theory of psychological discrimination. Psychometrika 40:77-105. CrossRef

Lo CC, Wang XJ (2006) Cortico-basal ganglia circuit mechanism for a decision threshold in reaction time tasks. Nat Neurosci 9:956-963. CrossRef Medline

Loftus GR, Masson ME (1994) Using confidence intervals in within-subject designs. Psychon Bull Rev 1:476-490. CrossRef Medline

Long M, Jiang W, Liu D, Yao H (2015) Contrast-dependent orientation discrimination in the mouse. Sci Rep 5:1-14. CrossRef Medline

Loughnane GM, Newman DP, Bellgrove MA, Lalor EC, Kelly SP, O’Connell 
RG (2016) Target selection signals influence perceptual decisions by modulating the onset and rate of evidence accumulation. Curr Biol 26: 496-502. CrossRef Medline

Louie K, Grattan LE, Glimcher PW (2011) Reward value-based gain control: divisive normalization in parietal cortex. J Neurosci 31:10627-10639. CrossRef Medline

Louie K, Khaw MW, Glimcher PW (2013) Normalization is a general neural mechanism for context-dependent decision making. Proc Natl Acad Sci U S A 110:6139-6144. CrossRef Medline

Luce RD (2008) Response times: their role in inferring elementary mental organization. Oxford: Oxford UP.

Luck SJ (2005) An introduction to the event-related potential technique. Cambridge, MA: Massachusetts Institute of Technology.

Lui LL, Bourne JA, Rosa MG (2013) Relationship between size summation properties, contrast sensitivity and response latency in the dorsomedial and middle temporal areas of the primate extrastriate cortex. PLoS One 8:e68276. CrossRef Medline

Makeig S, Bell JA, Jung TP, Sejnowski TJ (1996) Independent component analysis of electroencephalographic data. Adv Neural Inf Process Syst 8:145-151.

Mangun GR, Buck LA (1998) Sustained visual spatial attention produces costs and benefits in response time and evoked neural activity. Neuropsychologia 36:189-200. CrossRef Medline

Mangun GR, Hillyard SA (1987) The spatial allocation of visual attention as indexed by event-related brain potentials. Hum Factors 29:195-211. CrossRef Medline

Mangun GR, Hillyard SA (1988) Spatial gradients of visual attention: behavioral and electrophysiological evidence. Electroencephalogr Clin Neurophysiol 70:417-428. CrossRef Medline

Mayo JP, Maunsell JH (2016) Graded neuronal modulations related to visual spatial attention. J Neurosci 36:5353-5361. CrossRef Medline

McMains SA, Somers DC (2004) Multiple spotlights of attentional selection in human visual cortex. Neuron 42:677-686. CrossRef Medline

McMillen T, Holmes P (2006) The dynamics of choice among multiple alternatives. J Math Psychol 50:30-57. CrossRef

Müller MM, Andersen S, Trujillo NJ, Valdés-Sosa P, Malinowski P, Hillyard SA (2006) Feature-selective attention enhances color signals in early visual areas of the human brain. Proc Natl Acad Sci U S A 103:1425014254. CrossRef Medline

Murphy PR, Robertson IH, Harty S, O’Connell RG (2015) Neural evidence accumulation persists after choice to inform metacognitive judgments. Elife 4:1-23. CrossRef Medline

Murray SO, He S (2006) Contrast invariance in the human lateral occipital complex depends on attention. Curr Biol 16:606-611. CrossRef Medline

Nelli S, Itthipuripat S, Srinivasan R, Serences JT (2017) Fluctuations in instantaneous frequency predict alpha amplitude during visual perception. Nat Commun 8:2071. CrossRef Medline

Newman DP, Loughnane GM, Kelly SP, O'Connell RG, Bellgrove MA (2017) Visuospatial asymmetries arise from differences in the onset time of perceptual evidence accumulation. J Neurosci 37:3378-3385. CrossRef Medline

Newsome WT, Britten KH, Movshon JA (1989) Neuronal correlates of a perceptual decision. Nature 341:52-54. CrossRef Medline

Niwa M, Ditterich J (2008) Perceptual decisions between multiple directions of visual motion. J Neurosci 28:4435-4445. CrossRef Medline

Norcia AM, Appelbaum LG, Ales JM, Cottereau BR, Rossion B (2015) The steady-state visual evoked potential in vision research: a review. J Vis 15:1-46. CrossRef Medline

O'Connell RG, Dockree PM, Kelly SP (2012) A supramodal accumulationto-bound signal that determines perceptual decisions in humans. Nat Neurosci 15:1729-1735. CrossRef Medline

Palmer J (1994) Set-size effects in visual search: the effect of attention is independent of the stimulus for simple tasks. Vision Res 34:1703-1721. CrossRef Medline

Palmer J (1995) Attention in visual search: distinguishing four causes of a set-size effect. Curr Dir Psychol Sci 4:118-123. CrossRef

Pelli DG (1997) The VideoToolbox software for visual psychophysic: transforming numbers into movies. Spat Vis 10:437-442. CrossRef Medline

Pestilli F, Carrasco M, Heeger DJ, Gardner JL (2011) Attentional enhancement via selection and pooling of early sensory responses in human visual cortex. Neuron 72:832-846. CrossRef Medline

Purcell BA, Heitz RP, Cohen JY, Schall JD, Logan GD, Palmeri TJ (2010)
Neurally constrained modeling of perceptual decision making. Psychol Rev 117:1113-1143. CrossRef Medline

Purcell BA, Schall JD, Logan GD, Palmeri TJ (2012) From salience to saccades: multiple-alternative gated stochastic accumulator model of visual search. J Neurosci 32:3433-3446. CrossRef Medline

Ratcliff R, McKoon G (2008) The diffusion decision model: theory and data for two-choice decision tasks. Neural Comput 20:873-922. CrossRef Medline

Ratcliff R, Starns JJ (2013) Modeling confidence judgments, response times, and multiple choices in decision making: recognition memory and motion discrimination. Psychol Rev 120:697-719. CrossRef Medline

Reynaud A, Masson GS, Chavane F (2012) Dynamics of local input normalization result from balanced short- and long-range intracortical interactions in area V1. J Neurosci 32:12558-12569. CrossRef Medline

Reynolds JH, Heeger DJ (2009) The normalization model of attention. Neuron 61:168-185. CrossRef Medline

Roe RM, Busemeyer JR, Townsend JT (2001) Multialternative decision field theory: a dynamic connectionist model of decision making. Psychol Rev 108:370-392. CrossRef Medline

Roitman JD, Shadlen MN (2002) Response of neurons in the lateral intraparietal area during a combined visual discrimination reaction time task. J Neurosci 22:9475-9489. CrossRef Medline

Ross J, Speed HD, Morgan MJ (1993) The effects of adaptation and masking on incremental thresholds for contrast. Vision Res 33:2051-2056. CrossRef Medline

Rungratsameetaweemana N, Itthipuripat S, Salazar A, Serences JT (2018) Expectations do not alter early sensory processing during perceptual decision-making. J Neurosci 38:5632-5648. CrossRef Medline

Sereno MI, Dale AM, Reppas JB, Kwong KK, Belliveau JW, Brady TJ, Rosen BR, Tootell RB (1995) Borders of multiple visual areas in humans revealed by functional magnetic resonance imaging. Science 268:889-893. CrossRef Medline

Shadlen MN, Newsome WT (2001) Neural basis of a perceptual decision in the parietal cortex (area LIP) of the rhesus monkey. J Neurophysiol 86: 1916-1936. CrossRef Medline

Smith PL, Ratcliff R (2004) Psychology and neurobiology of simple decisions. Trends Neurosci 27:161-168. CrossRef Medline

Squires KC, Hillyard SA, Lindsay PH (1973) Cortical potentials evoked by confirming and disconfirming feedback following an auditory discrimination. Percept Psychophys 13:25-31. CrossRef

Squires NK, Squires KC, Hillyard SA (1975) Two varieties of long-latency positive waves evoked by unpredictable auditory stimuli in man. Electroencephalogr Clin Neurophysiol 38:387-401. CrossRef Medline

Stanislaw H, Todorov N (1999) Calculation of signal detection theory measures. Behav Res Methods Instrum Comput 31:137-149. CrossRef Medline

Störmer VS, Alvarez GA (2014) Feature-based attention elicits surround suppression in feature space. Curr Biol 24:1985-1988. CrossRef Medline

Störmer VS, Alvarez GA (2016) Attention alters perceived attractiveness. Psychol Sci 27:563-571. CrossRef Medline

Störmer VS, Winther GN, Li SC, Andersen SK (2013) Sustained multifocal attentional enhancement of stimulus processing in early visual areas predicts tracking performance. J Neurosci 33:5346-5351. CrossRef Medline

Sun S, Yu R, Wang S (2017) A neural signature encoding decisions under perceptual ambiguity. Eneuro 4:ENEURO.0235-17.2017. CrossRef Medline

Sundberg KA, Mitchell JF, Reynolds JH (2009) Spatial attention modulates center-surround interactions in macaque visual area V4. Neuron 61:952963. CrossRef Medline

Toffanin P, de Jong R, Johnson A, Martens S (2009) Using frequency tagging to quantify attentional deployment in a visual divided attention task. Int J Psychophysiol 72:289-298. CrossRef Medline

Tsubomi H, Fukuda K, Watanabe K, Vogel EK (2013) Neural limits to representing objects still within view. J Neurosci 33:8257-8263. CrossRef Medline

Twomey DM, Murphy PR, Kelly SP, O’Connell RG (2015) The classic P300 encodes a build-to-threshold decision variable. Eur J Neurosci 42:16361643. CrossRef Medline

Twomey DM, Kelly SP, O'Connell RG (2016) Abstract and effectorselective decision signals exhibit qualitatively distinct dynamics before 
delayed perceptual reports. J Neurosci 36:7346-7352. CrossRef Medline

Wang HX, Movshon JA (2016) Properties of pattern and component direction-selective cells in area MT of the macaque. J Neurophysiol 115: 2705-2720. CrossRef Medline

Wang J, Wade AR (2011) Differential attentional modulation of cortical responses to S-cone and luminance stimuli. J Vis 11:1-15. CrossRef Medline

Wang XJ (2012) Neural dynamics and circuit mechanisms of decisionmaking. Curr Opin Neurobiol 22:1039-1046. CrossRef Medline

White AL, Runeson E, Palmer J, Ernst ZR, Boynton GM (2017) Evidence for unlimited capacity processing of simple features in visual cortex. J Vis 17:19. CrossRef Medline

Woodman GF (2010) A brief introduction to the use of event-related po- tentials (ERPs) in studies of perception and attention. Atten Percept Psychophysiol 72:1-29. CrossRef Medline

Woodman GF, Arita JT, Luck SJ (2009) A cuing study of the N2pc component: an index of attentional deployment to objects rather than spatial locations. Brain Res 1297:101-111. CrossRef Medline

Wyart V, Myers NE, Summerfield C (2015) Neural mechanisms of human perceptual choice under focused and divided attention. J Neurosci 35: 3485-3498. CrossRef Medline

Zhang X, Japee S, Safiullah Z, Mlynaryk N, Ungerleider LG (2016) A normalization framework for emotional attention. PLoS Biol 14:e1002578. CrossRef Medline

Zoccolan D, Cox DD, DiCarlo JJ (2005) Multiple object response normalization in monkey inferotemporal cortex. J Neurosci 25:8150-8164. CrossRef Medline 